\title{
Role of endoscopy in primary sclerosing cholangitis: European Society of Gastrointestinal Endoscopy (ESGE) and European Association for the Study of the Liver (EASL) Clinical Guideline
}

Authors

Lars Aabakken ${ }^{1}$, Tom H. Karlsen², Jörg Albert ${ }^{3}$, Marianna Arvanitakis ${ }^{4}$, Olivier Chazouilleres ${ }^{5}$, Jean-Marc Dumonceau6 , Martti Färkkilä7, Peter Fickert ${ }^{8}$, Gideon M. Hirschfield ${ }^{9}$, Andrea Laghi ${ }^{10}$, Marco Marzioni ${ }^{11}$, Michael Fernandez ${ }^{4}$, Stephen P. Pereira ${ }^{12}$, Jürgen Pohl ${ }^{13}$, Jan-Werner Poley ${ }^{14}$, Cyriel Y. Ponsioen ${ }^{15}$, Christoph Schramm ${ }^{16}$, Fredrik Swahn ${ }^{17}$, Andrea Tringali ${ }^{18}$, Cesare Hassan ${ }^{19}$

Institutions

1 Gl Endoscopy, Rikshospitalet University Hospital, Hospital, and Faculty of Medicine, University of Oslo, Oslo, Norway

2 Norwegian PSC Research Center and Section for Gastroenterology, Department of Transplantation Medicine, Division of Cancer Medicine, Surgery and Transplantation, Oslo University Hospital, Rikshospitalet, and Institute of Clinical Medicine, University of Oslo, Oslo, Norway

3 Abteilung für Gastroenterologie, Hepatologie und Endokrinologie, Robert-Bosch-Krankenhaus, Stuttgart, Germany

4 Department of Gastroenterology, Hepatopancreatology and Digestive Oncology, Erasme Hospital, Université Libre de Bruxelles, Brussels, Belgium

5 Service d'Hépatologie, Hôpital Saint-Antoine, Assistance Publique - Hôpitaux de Paris, Centre de référence des maladies inflammatoires du foie et des voies biliaires, Filière Maladies Rares du Foie de l'Adulte et de l'Enfant (FILFOIE), UPMC UNIV Paris 06, France

6 Gedyt Endoscopy Center, Buenos Aires, Argentina

7 Department of Gastroenterology, Helsinki University Central Hospital, Helsinki, Finland

8 Research Unit for Experimental and Molecular Hepatology, Division of Gastroenterology and Hepatology, Department of Internal Medicine, Medical University of Graz, Austria

9 National Institute for Health Research (NIHR), Birmingham Liver Biomedical Research Unit (BRU), and Centre for Liver Research, University of Birmingham, Birmingham, United Kingdom

10 Pathological Sciences, Sapienza-University, Rome, Italy

11 Clinic of Gastroenterology and Hepatology, Università Politecnica delle Marche - Ospedali Riuniti University Hospital, Ancona, Italy

12 Institute for Liver and Digestive Health, University College London, Royal Free Campus, London, UK
13 Department of Gastroenterology and Interventional Endoscopy, Klinikum Friedrichshain, Berlin, Germany

14 Department of Gastroenterology and Hepatology, Erasmus MC, University Medical Center, Rotterdam, The Netherlands

15 Department of Gastroenterology and Hepatology, Academic Medical Center, Amsterdam, The Netherlands

16 Department of Medicine I and Martin Zeitz Centre for Rare Diseases, University Medical Center HamburgEppendorf, Hamburg, Germany

17 Center for Digestive Diseases, Karolinska University Hospital and Division of Surgery, CLINTEC, Karolinska Institute, Stockholm, Sweden

18 Digestive Endoscopy Unit, Catholic University, Rome, Italy

19 Digestive Endoscopy Unit, Nuovo Regina Margherita Hospital, Rome, Italy

Bibliography

DOI http://dx.doi.org/10.1055/s-0043-107029

Published online: 18.4.2017 | Endoscopy 2017; 49: 588-608

(c) Georg Thieme Verlag KG Stuttgart · New York

ISSN 0013-726X

This Guideline was developed by the EASL and the ESGE and is published simultaneously in the journals Endoscopy and Journal of Hepatology. (c) 2017 Georg Thieme Verlag KG, and (c) 2017 European Association for the Study of the Liver, published by Elsevier. All rights reserved.

Corresponding author

Professor Lars Aabakken, Department of Medical

Gastroenterology, Oslo University Hospital-Rikshospitalet,

N-0027 Oslo, Norway

lars.aabakken@medisin.uio.no

Appendix e1

Online content viewable at: https://www.thieme-connect.com/ DOI/DOI?10.1055/s-0043-107029

Aabakken L et al. Role of endoscopy... Endoscopy 2017; 49: 588-608 


\section{MAIN RECOMMENDATIONS}

1 ESGE/EASL recommend that, as the primary diagnostic modality for PSC, magnetic resonance cholangiography (MRC) should be preferred over endoscopic retrograde cholangiopancreatography (ERCP).

Moderate quality evidence, strong recommendation.

2 ESGE/EASL suggest that ERCP can be considered if MRC plus liver biopsy is equivocal or contraindicated in patients with persisting clinical suspicion of PSC. The risks of ERCP have to be weighed against the potential benefit with regard to surveillance and treatment recommendations.

Low quality evidence, weak recommendation.

6 ESGE/EASL suggest that, in patients with an established diagnosis of PSC, MRC should be considered before therapeutic ERCP.

Weak recommendation, low quality evidence.

7 ESGE/EASL suggest performing endoscopic treatment with concomitant ductal sampling (brush cytology, endobiliary biopsies) of suspected significant strictures identified at MRC in PSC patients who present with symptoms likely to improve following endoscopic treatment.

Strong recommendation, low quality evidence.
9 ESGE/EASL recommend weighing the anticipated benefits of biliary papillotomy/sphincterotomy against its risks on a case-by-case basis.

Strong recommendation, moderate quality evidence.

Biliary papillotomy/sphincterotomy should be considered especially after difficult cannulation.

Strong recommendation, low quality evidence.

16 ESGE/EASL suggest routine administration of prophylactic antibiotics before ERCP in patients with PSC.

Strong recommendation, low quality evidence.

17 EASL/ESGE recommend that cholangiocarcinoma (CCA) should be suspected in any patient with worsening cholestasis, weight loss, raised serum CA19-9, and/or new or progressive dominant stricture, particularly with an associated enhancing mass lesion.

Strong recommendation, moderate quality evidence.

19 ESGE/EASL recommend ductal sampling (brush cytology, endobiliary biopsies) as part of the initial investigation for the diagnosis and staging of suspected CCA in patients with PSC.

Strong recommendation, high quality evidence.
This Guideline is an official statement of the European Society of Gastrointestinal Endoscopy (ESGE) and of the European Association for the Study of the Liver (EASL) on the role of endoscopy in primary sclerosing cholangitis. The Grading of Recommendations Assessment, Development and Evaluation (GRADE) system was adopted to define the strength of recommendations and the quality of evidence.

\section{Introduction}

Primary sclerosing cholangitis (PSC) is a chronic bile duct disease with an estimated prevalence in the range of 1 to 16 per 100000 with significant regional differences across Europe. The prevalence of PSC is increased in patients with ulcerative colitis and estimated to be in the range $1 \%-5 \%$ [1]. Magnetic resonance imaging (MRI) studies have shown that the prevalence of imaging changes compatible with PSC in ulcerative colitis is almost fourfold higher than that detected based on clinical assessments [2]. PSC is more common in men (comprising $60 \%-70 \%$ of patients) and most patients present with pancolitis, often with a right-sided predominance [3-5]. A major challenge in the clinical management of patients is a highly increased and unpredictable risk of biliary and colonic malignancies.

The diagnosis of PSC is based on the combination of clinical, laboratory, imaging, and histological findings. Briefly, a diagnostic work-up for PSC should be performed in all patients with inflammatory bowel disease (IBD) and abnormal liver biochemistry test findings, especially elevated alkaline phosphatase (ALP) and gamma glutamyl transferase (GGT) values, as well as in non-IBD patients with elevated cholestatic liver en- zymes not otherwise explained. A proposed algorithm for PSC diagnosis has already been presented by earlier European Association for the Study of the Liver (EASL) guidelines [6], and comprehensive discussion of issues unrelated to the use of endoscopy in PSC will not be addressed in the present Guideline.

Endoscopic retrograde cholangiopancreatography (ERCP) plays a significant role in the handling of PSC because of its high accuracy and prognostic value as well as its sampling and therapeutic possibilities. However, ERCP must be integrated within well-defined clinical algorithms together with less invasive or noninvasive imaging and biochemical tests. In particular, the widespread implementation of magnetic resonance cholangiography (MRC) has led to increasing restriction of the use of ERCP to cases where the diagnosis is equivocal or when sampling or endoscopic treatment are required.

The aim of this evidence- and consensus-based Guideline, commissioned by the European Society of Gastrointestinal Endoscopy (ESGE) and the EASL, is to provide practical advice on how to utilize ERCP and colonoscopy in PSC patients, in order to maximize their benefit and minimize their burden and adverse events.

\section{Methods}

The ESGE and the EASL commissioned this Guideline and appointed panel representatives from both societies to participate in the project development. The Guideline development process included meetings and online discussions among members of the Guideline committee during January-April 2015 and July 2016. Key questions (see Appendix 1, online- 


$\begin{array}{ll}\text { ABBREVIATIONs } \\ \text { ALP } & \text { alkaline phosphatase } \\ \text { ASGE } & \text { American Society for Gastrointestinal Endoscopy } \\ \text { CCA } & \text { cholangiocarcinoma } \\ \text { CI } & \text { confidence interval } \\ \text { CRC } & \text { colorectal cancer } \\ \text { CT } & \text { computed tomography } \\ \text { EASL } & \text { European Association for the Study of the Liver } \\ \text { ECCO } & \text { European Crohn's and Colitis Organisation } \\ \text { ERC } & \text { endoscopic retrograde cholangiography } \\ \text { ERCP } & \text { endoscopic retrograde cholangiopancreato- } \\ & \text { graphy } \\ \text { ESGE } & \text { European Society of Gastrointestinal Endoscopy } \\ \text { FISH } & \text { fluorescence in situ hybridization } \\ \text { GGT } & \text { gamma glutamyl transferase } \\ \text { GRADE } & \text { Grading of Recommendations Assessment, } \\ & \text { Development and Evaluation } \\ \text { HGD } & \text { high grade dysplasia } \\ \text { IBD } & \text { inflammatory bowel disease } \\ \text { IDUS } & \text { intraductal ultrasound } \\ \text { LGD } & \text { low grade dysplasia } \\ \text { MRC } & \text { magnetic resonance cholangiography } \\ \text { MRCP } & \text { magnetic resonance cholangiopancreatography } \\ \text { MRI } & \text { magnetic resonance imaging } \\ \text { NLR } & \text { negative likelihood ratio } \\ \text { NPV } & \text { negative predictive value } \\ \text { NSAID } & \text { nonsteroidal anti-inflammatory drug } \\ \text { OR } & \text { odds ratio } \\ \text { PBC } & \text { primary biliary cholangitis } \\ \text { PCLE } & \text { probe-based confocal laser endomicroscopy } \\ \text { PLR } & \text { positive likelihood ratio } \\ \text { POCS } & \text { peroral cholangioscopy } \\ \text { PPV } & \text { positive predictive value } \\ \text { PSC } & \text { primary sclerosing cholangitis } \\ \text { PTBD } & \text { percutaneous transhepatic biliary drainage } \\ \text { RCT } & \text { randomized controlled trial } \\ \text { RR } & \text { relative risk } \\ & \end{array}$

only) were prepared by the coordinating team. A systematic literature search in PubMed/MEDLINE and the Cochrane Library was conducted, using at a minimum the search terms "Primary Sclerosing Cholangitis" and "Endoscopy," and "Colonoscopy" for the part related to the diagnosis and surveillance of IBD in PSC. Articles were first selected by title, their relevance was then assessed by review of full-text articles, and publications with content that was considered irrelevant were excluded. Aspects related to endoscopy in PSC patients after liver transplantation were omitted. Evidence tables were generated for each key question, summarizing the quality of the evidence of the available studies. The entire process was performed according to the Grading of Recommendations Assessment, Development and Evaluation (GRADE) system [7]. Draft proposals were presented to the entire group for general discussion and voting, during a plenary meeting held in November 2015.

In May 2016, a compiled manuscript prepared by L.A. and T.H.K. was sent to all group members. After revisions and agreement on a final version, the manuscript was submitted for peer review. The revised manuscript was approved by all authors and the governing boards of ESGE and EASL and was subsequently forwarded to Endoscopy and the Journal of Hepatology for publication.

\section{Endoscopic diagnosis and surveillance of PSC}

\section{Diagnosis of PSC}

\section{RECOMMENDATION}

1. ESGE/EASL recommend that, as the primary diagnostic modality for PSC, magnetic resonance cholangiography (MRC) should be preferred over endoscopic retrograde cholangiopancreatography (ERCP).

Moderate quality evidence, strong recommendation.

Although ERCP has been regarded as the standard of reference in diagnosing PSC, MRC is now recommended as a firstline noninvasive imaging method for patients with suspected PSC that offers comparable accuracy (except in early-stage PSC restricted to intrahepatic bile ducts, and in the rare cases of contraindications to MRC) [8-12]. A meta-analysis based on 6 studies using ERCP as a reference method concluded that MRC has high sensitivity and specificity $(0.86$ and 0.94 , respectively) for the diagnosis of PSC [13]. According to a decision model comparing different approaches in the work-up of patients with suspected PSC [14], the strategy of initial MRC, followed by ERCP only in selected cases (e.g. ambiguous MRC findings), is the most cost-effective approach [14, 15].

The ductographic features defining PSC are described below but a number of other diseases of the biliary tree may present similar features ( Table 1 ). The specificity of the cholangiographic features of PSC without the additional diagnostic clinical and biochemical clues is poor [16].

Of note, the visualization of the distal common bile duct and the peripheral intrahepatic ducts is still suboptimal using MRC $[10,12]$. One study has suggested that a numerical score calculated on the basis of three-dimensional MRC may predict progression of bile duct changes, but the study lacked ERCP reference [17]. A diagnostic MRC, because of its very high specificity for the diagnosis of PSC when diagnostic clinical and biochemical clues are present, obviates a confirmatory ERCP unless therapeutic procedures or ductal sampling are indicated $[13,18]$.

\section{RECOMMENDATION}

2. ESGE/EASL suggest that ERCP can be considered if MRC plus liver biopsy is equivocal or contraindicated in patients with persisting clinical suspicion of PSC. The risks of ERCP have to be weighed against the potential benefit with regard to surveillance and treatment recommendations.

Low quality evidence, weak recommendation. 
- Table 1 Classification of secondary sclerosing cholangitis and conditions that may mimic primary sclerosing cholangitis on cholangiography.

\begin{tabular}{|c|c|}
\hline \multirow[t]{2}{*}{ Infection } & Bacterial/parasitic cholangitis \\
\hline & Recurrent pyogenic cholangitis \\
\hline \multirow{4}{*}{$\begin{array}{l}\text { Immunodeficiency- } \\
\text { related (infections) }\end{array}$} & Congenital immunodeficiency \\
\hline & Acquired immunodeficiency (e.g. HIV) \\
\hline & Combined immunodeficiencies \\
\hline & Angioimmunoblastic lymphadenopathy \\
\hline \multirow[t]{4}{*}{ Mechanical/toxic } & Cholelithiasis/choledocholithiasis \\
\hline & Surgical bile duct trauma \\
\hline & Intra-arterial chemotherapy \\
\hline & Drug-induced sclerosing cholangitis \\
\hline \multirow[t]{3}{*}{ Ischemic } & Vascular trauma \\
\hline & Hepatic allograft arterial insufficiency \\
\hline & Paroxysmal nocturnal hemoglobinuria \\
\hline \multirow{4}{*}{$\begin{array}{l}\text { Other pancreatico- } \\
\text { biliary disease }\end{array}$} & Cystic fibrosis \\
\hline & Sclerosing cholangitis of critical illness \\
\hline & $A B C B 4$-associated cholangiopathy \\
\hline & Chronic pancreatitis \\
\hline \multirow{4}{*}{$\begin{array}{l}\text { Systemic inflam- } \\
\text { matory diseases }\end{array}$} & IgG4-associated systemic disease \\
\hline & Hypereosinophilic syndrome \\
\hline & Sarcoidosis \\
\hline & Graft-versus-host disease \\
\hline \multirow{10}{*}{$\begin{array}{l}\text { Potentially } \\
\text { mimicking on } \\
\text { cholangiography }\end{array}$} & Langerhans cell histiocytosis \\
\hline & Systemic mastocytosis \\
\hline & Caroli's disease \\
\hline & Congenital hepatic fibrosis \\
\hline & Other types of ductal plate abnormalities \\
\hline & Hodgkin's disease \\
\hline & Cholangitis glandularis proliferans \\
\hline & Neoplastic/metastatic disease \\
\hline & Amyloidosis \\
\hline & Hepatic allograft rejection \\
\hline
\end{tabular}

HIV, human immunodeficiency virus; IgG4, immunoglobulin G4.

Whether or not to perform ERCP in patients with high quality normal findings at MRC depends on the level of clinical suspicion for PSC and on the impact of the diagnosis on patient management and prognosis. ERCP is regarded as unnecessary in patients with a low level of clinical suspicion, but it could be considered in patients with an intermediate or high level of clinical suspicion, as suggested by a meta-analysis of MRC diagnostic performance [13]. However, this meta-analysis included only studies performed prior to 2007. The continuous improvement in MRC quality due to use of higher magnetic fields, as exemplified by the ability to visualize third- and fourth-order intrahepatic ducts as well as the availability of three-dimensional image acquisition, is likely to further decrease the probability of abnormal ERCP findings in patients with normal MRC results. In addition, as detailed reports including the clinical, biochemical, and histological characteristics and outcomes of these patients with negative MRC but positive ERCP findings are lacking, the clinical benefit of ERCP can be questioned in this setting. If high quality MRC images are not available, or in equivocal cases, it is reasonable to consider patient referral to centers with known technical expertise with MRC as a first step [19], followed by liver biopsy. If high quality MRC images and liver biopsy still cannot definitely exclude or confirm the presence of PSC, ERCP can be considered in patients with persisting clinical suspicion for the diagnosis, to take advantage of the filling pressure obtained by the balloon occlusion and the slight superiority as to visualization of the extrahepatic bile ducts.

\section{Ductographic criteria for PSC}

The first ERCP criteria for ductographic changes in PSC were published in 1984 by Li-Yeng \& Goldberg [20]. Typical changes seen in PSC consist of minor irregularities of duct contour and local narrowing with pre-stenotic dilatation (type I), threadlike narrowings alternating with normal caliber of bile ducts or slight dilatation (type II), multiple strictures with saccular dilatations (type III), and the most advanced changes consisting of advanced ductal narrowing with resultant lack of filling of the peripheral ducts (type IV). The classification has later been modified by Majojie et al. [21] and Ponsioen et al. [22, 23]. The classification of Ponsioen et al. [23] has been validated and shown to correlate with patient prognosis ( $>$ Table 2 ). Another type of classification is based on evaluation of the grade, length, and extent of strictures, the degree of bile duct dilatation, and the distribution of lesions [24].

None of the ductographic criteria published are specific for PSC and the findings must be interpreted in the context of patient demographic data and the clinical features. Review by teams with expertise in complex biliary disease is often useful, as multiple secondary causes of sclerosing cholangitis must be considered [25] (> Table 3 ).

\section{Unusual cholangiographic features}

Some PSC patients may present with cystic dilatations of intrahepatic bile ducts simulating Caroli's disease [10]. Of note, the fusiform and small cystic dilatations of intrahepatic (mostly peripheral) bile ducts, as observed in patients with congenital hepatic fibrosis and autosomal recessive polycystic kidney disease, should not be misdiagnosed as PSC [11].

Another differential diagnosis is the peculiar cholangiographic phenotype of adult forms of ABCB4/MDR3 deficiency which may be characterized by large unifocal or multifocal spindle-shaped intrahepatic bile duct dilatations with or without apparent bile duct stenosis [12, 26]. This diagnosis should be suspected on familial clustering of excessive gallstone disease and often a history of prior cholecystectomy at age $<40$ years 
and associated intrahepatic cholestasis of pregnancy, and is confirmed by $A B C B 4$ genotyping.

\section{RECOMMENDATION}

3. For the diagnosis of PSC, ESGE/EASL do not suggest routine use of endoscopic techniques other than ERCP (i.e., endoscopic ultrasound including intraductal ultrasound [IDUS], cholangioscopy, confocal endomicroscopy).

Weak recommendation, low quality evidence.

In the diagnosis of PSC there is no established role for endoscopic techniques beyond ERCP, e.g. brush cytology, ductal biopsy, cholangioscopy, or confocal laser endomicroscopy. In selected cases with suspected extrahepatic disease and inconclusive MRC findings, endoscopic ultrasound (including IDUS) and elastography may add information on common bile duct strictures, wall thickening, and liver fibrosis stage [27 - 30].

\section{ERCP in established PSC}

\section{RECOMMENDATION}

4. ESGE/EASL suggest that a dominant stricture at ERCP should be defined as a stenosis with a diameter of $\leq 1.5 \mathrm{~mm}$ in the common bile duct and/or $\leq 1.0 \mathrm{~mm}$ in an hepatic duct within $2 \mathrm{~cm}$ of the main hepatic confluence. Weak recommendation, low quality evidence.

Deciding on the clinical impact of a bile duct stricture may be challenging. The "dominant stricture" denomination arose alongside the term "major stricture" early in the history of endoscopic management of PSC [31]. The "major" or "dominant" stricture terms were initially used more broadly, pertaining to strictures of the common bile duct and right and left bifurcation of the hepatic ducts (extrahepatic PSC lesions), since these were found to be more prone to clinical events than intrahepatic strictures [31, 32]. The precise definition of a dominant stricture was introduced by Stiehl et al. in 2002 for use in endoscopic studies as a severity measure [33, 34], although it employs a somewhat arbitrary value, depending, for example, on filling pressure. A number of endoscopic studies, both before and after 2002, do not apply the diameter criterion strictly when determining a dominant stricture $[35,36]$, and focus on suspected clinical relevance. Determination of the clinical significance and potential benefit from endoscopic interventions should therefore not be based on this definition alone, and the decision for intervention rather considered as a compound clinical decision.

Multiple dominant strictures can be found in the same patient (12\% in the study by Bjornsson et al.) [34].

Of note, the ERCP definition of a dominant stricture is usually considered to be not applicable to MRC, in particular in the extrahepatic ducts, given the insufficient spatial resolution of MRC $[10,17]$ and the lack of the hydrostatic pressure that is present during ERCP.

A complete occlusion cholangiogram should generally be obtained if an ERCP is performed, because it adds little risk to the ERCP, decreases variability, and may reveal that a dominant stricture suspected at MRC is indeed not a stricture [37].

\section{RECOMMENDATION}

5. ESGE/EASL suggest ERCP and ductal sampling (brush cytology, endobiliary biopsies) should be considered in established PSC in the case of: (i) clinically relevant or worsening symptoms (jaundice, cholangitis, pruritus); (ii) rapid increase of cholestatic enzyme levels; or (iii) new dominant stricture or progression of existing dominant strictures identified at MRC in the context of appropriate clinical findings.

Weak recommendation, low quality evidence.

ERCP can be indicated in patients with a confirmed diagnosis of PSC when changes in clinical, laboratory, and radiological findings occur during the course of the disease. The purpose is to make an assessment of the likelihood of the presence of biliary dysplasia as a risk factor for cholangiocarcinoma (CCA) and to identify biliary strictures amenable to intervention.

\section{(i) Clinical events}

In the early stage of PSC, dominant biliary strictures are usually asymptomatic. Exacerbation of jaundice (not related to liver failure), episodes of fever and chills suggestive of cholangitis, or worsening of pruritus are indications for ERCP for the treat-

- Table 2 Amsterdam classification of cholangiographic changes in primary sclerosing cholangitis (PSC) [23].

\begin{tabular}{|c|l|l|}
\hline Type & Intrahepatic & Extrahepatic \\
\hline 0 & No visible abnormalities & No visible abnormalities \\
\hline I & Multiple caliber changes; minimal dilatation & Slight irregularities of duct contour; no stricture \\
\hline II & Multiple strictures; saccular dilatations, decreased arborization & Segmental strictures \\
\hline III & $\begin{array}{l}\text { Only central branches filled despite adequate filling pressure; } \\
\text { severe pruning }\end{array}$ & Strictures of almost entire length of duct \\
\hline IV & - & Extremely irregular margins; diverticulum-like outpouchings \\
\hline
\end{tabular}


- Table 3 Characteristic cholangiographic features in primary sclerosing cholangitis (PSC) and other ductal diseases.

\begin{tabular}{|l|l|}
\hline Diagnosis & Main cholangiographic features \\
\hline PSC & $\begin{array}{l}\text { Multifocal intrahepatic and extrahepatic } \\
\text { bile duct strictures ("beaded" appearance), } \\
\text { slight biliary dilatation, diverticular out- } \\
\text { pouchings, "pruned tree" appearance at } \\
\text { chronic stage }\end{array}$ \\
\hline $\begin{array}{l}\text { Ascending } \\
\text { cholangitis }\end{array}$ & $\begin{array}{l}\text { Multiple intrahepatic bile duct strictures, } \\
\text { stones, biliary abscesses }\end{array}$ \\
\hline Ischemic cholangitis & $\begin{array}{l}\text { Proximal intrahepatic bile duct strictures, } \\
\text { bile duct necrosis, biliomas, abscesses, } \\
\text { biliary cast }\end{array}$ \\
\hline Caustic cholangitis & $\begin{array}{l}\text { Localized intrahepatic bile duct strictures, } \\
\text { irregularities of bile duct wall }\end{array}$ \\
\hline AIDS-related & $\begin{array}{l}\text { Stricture of the distal common bile duct, } \\
\text { papillitis, acalculous cholecystitis }\end{array}$ \\
\hline cholangitis & $\begin{array}{l}\text { Multifocal central bile duct strictures, bile } \\
\text { duct wall thickening with visible lumen, } \\
\text { pancreatic abnormalities compatible with } \\
\text { autoimmune pancreatitis }\end{array}$ \\
\hline $\begin{array}{l}\text { IgG4-related } \\
\text { cholangitis }\end{array}$ & $\begin{array}{l}\text { Central and extrahepatic bile duct } \\
\text { irregularities }\end{array}$ \\
\hline Portal biliopathy
\end{tabular}

ment of dominant strictures and to perform ductal brush sampling to exclude malignancy $[8,38]$. Worsening pain in the right upper abdominal quadrant, fatigue, and weight loss also need careful evaluation.

\section{(ii) Laboratory results}

Serum laboratory tests are neither sensitive nor specific enough to evaluate PSC progression [38], but in the case of rapid increase of serum bilirubin levels and/or cholestatic liver enzymes (serum ALP, serum GGT) ERCP is indicated [6], especially in patients with a diagnosis of clinically significant hilar or extrahepatic strictures on MRC. Elevation of serum CA19-9 in PSC patients has an unsatisfactory sensitivity (14\%) and positive predictive value (PPV) (67\%) for the diagnosis of CCA [36, 38, 39], and is not helpful in selecting patients for ERCP.

\section{(iii) Progression/new-onset clinically significant strictures on MRC}

Progressive intrahepatic or extrahepatic bile duct dilatation on imaging studies (ultrasound or MRC) is an indication for ERCP with ductal sampling [6]. A careful evaluation of new-onset dominant strictures in PSC is recommended, because of the increased risk of CCA in this situation.

In detail, a stricture that is disproportionately severe relative to others, concomitant biliary filling defects, marked biliary dilatation ( $\geq 2 \mathrm{~cm}$ for the common bile duct, $\geq 1 \mathrm{~cm}$ for the right or left intrahepatic ducts, $\geq 5 \mathrm{~mm}$ for other intrahepatic ducts) suggests CCA [40]. Conversely, this risk was low in patients without dominant strictures according to a 25-year experience [41]. Abnormal cytological findings, such as suspicion of malignancy or aneuploid DNA findings need a close follow-up by
ERCP with repeated sampling, unless urgent liver transplantation is considered to be warranted.

The utility of ERCP in handling dominant strictures was shown in a prospective study [42] on 171 PSC patients followed for 20 years: repeated endoscopic therapy was associated with a transplant-free survival of $81 \%$ at 5 years and $52 \%$ at 10 years after initial endoscopic therapy. In this population, a $6 \%$ CCA rate was found in patients with dominant strictures.

\section{RECOMMENDATION}

6. ESGE/EASL suggest that, in patients with an established diagnosis of PSC, MRC should be considered before therapeutic ERCP.

Weak recommendation, low quality evidence.

MRC may be useful to confirm the indication, to exclude focal parenchymal changes, and to give the clinicians performing the ERCP imaging-based guidance to minimize the risk of complications. Regarding MRC in established PSC, a retrospective single-center study reported a $76 \%$ accuracy of MRC in the diagnosis of CCA complicating PSC [40]. For these reasons, patients with an established diagnosis of PSC should have an MRC examination in their clinical records $[13,43]$.

\section{RECOMMENDATION}

7. ESGE/EASL suggest performing endoscopic treatment with concomitant ductal sampling (brush cytology, endobiliary biopsies) of suspected significant strictures identified at MRC in PSC patients who present with symptoms likely to improve following endoscopic treatment. Strong recommendation, low quality evidence.

Selected series reporting on endoscopic treatment in PSC patients are summarized in $>$ Table 4 ; none of these compared performance versus no performance of endoscopic treatment for dominant stricture. The benefits reported following dilation of dominant stricture included short-term improvement of symptoms and of liver biochemical test results, as well as a longer liver transplantation-free survival compared to that predicted using the Mayo clinical risk model. Similar findings have also been reported in several smaller case series [32,47-50].

The main criticisms of these studies are as follows:

a) The Mayo clinical risk model was not designed to evaluate patients with dominant stricture; specifically, many patients underwent therapeutic ERCP because of elevated bilirubin, which is part of the Mayo risk score and went down in most patients after the intervention. Hence, baseline Mayo risk score was not determined in a steady-state situation.

b) Serum test results for cholestasis may spontaneously fluctuate in patients with PSC complicated or not with a dominant stricture. In 125 PSC patients, Bjornsson et al. reported changes in serum ALP and serum bilirubin from baseline up to 12 months following ERCP. As patients with dominant 
stricture received no stricture dilation, the authors stated that "If our patients had been consequently dilated or stented the decrease in bilirubin and clinical features at followup would have been attributed to endoscopic therapy" [34]. However, in that study, the variations reported in ALP and in total serum bilirubin after versus before ERCP were not significant, in contrast with various studies listed in $>$ Table 4 that used dominant stricture dilation/stenting. Also, it was not clear on what basis these patients were treated conservatively, while others did receive endoscopic therapy.

Other limitations of most studies listed in $>$ Table 4 include retrospective design, selection bias, and reporting of results for a mixture of treatments, namely dilation with and without stenting of dominant strictures as well as, in a minority of patients, treatment with ursodeoxycholic acid started during follow-up.

A critical issue is that potential benefits must be weighed against the certain risks of therapeutic ERCP in patients with no other therapeutic option except liver transplantation. Symptoms likely to improve following dominant stricture treatment generally include pruritus, pain, cholangitis, and jaundice in patients with a significant $(\geq 20 \%)$ increase in cholestasis, while in patients with end-stage liver disease, only cholangitis is expected to improve.

Finally, patients with advanced liver disease with cirrhosis may not benefit from endoscopic treatment. Ahrendt et al. reported no change in serum bilirubin at 1 year following endoscopic and/or percutaneous stricture dilation in 10 patients with cirrhosis and a baseline serum bilirubin $\geq 5 \mathrm{mg} / \mathrm{dL}$ [51]. Death following endoscopic balloon dilation of dominant stricture has been reported in a patient with PSC and end-stage liver disease [46]. Diagnostic ERCP was followed by deterioration of cholestasis in 7 of 8 patients with more advanced PSC at biopsy (Ludwig stage III or IV) versus 1 of 7 with less advanced disease (Ludwig stage I or II) [52].

\section{Balloon dilation versus stent therapy}

\section{RECOMMENDATION}

8. ESGE/EASL suggest that the choice between stenting and balloon dilation should be left to the endoscopist's discretion.

Weak recommendation, low quality evidence.

Results from selected series reporting on endoscopic treatment of dominant strictures in PSC are summarized in > Table 4. Of note: (i) in the majority of studies that reported on balloon dilation for dominant stricture, stents were inserted in a minority of patients; (ii) a significant improvement in liver transplantation-free survival compared with the Mayo model has been reported only with balloon dilation; and (iii) the perforation rate has been higher with stenting compared with balloon dilation.

A single retrospective study compared balloon dilation versus balloon dilation combined with stenting for dominant stric- ture in PSC patients ( $n=34$ and $n=37$, respectively) [46]. The "balloon dilation alone" group was treated by endoscopic means only, while 23 patients (62\%) in the "stenting" group underwent percutaneous treatment because of failed endoscopic access and/or dominant stricture dilation. Serum bilirubin decreased similarly in both groups of patients, but more procedures and more complications were recorded in the stent versus the balloon dilation group (median number of procedures per patient, 5.0 vs. 2.1, respectively; patients with complications, $54 \%$ vs. $15 \%$, respectively). Complications included bile duct perforation in 7 patients (10\%), 5 of whom were in the stent group. However, it is difficult to draw conclusions because of the different access routes used (percutaneous in $62 \%$ in the stent group vs. 0 in the balloon dilation group), a selection bias due to more severe stricture in the stent group, and the long stenting duration used (mean 3 months) putting the patient at high risk for stent clogging and cholangitis. A short stenting duration (see recommendation 13) is currently the standard of care.

The European multicenter randomized DILSTENT trial comparing single-balloon dilatation versus short-term stenting was prematurely stopped recently after a planned interim analysis. Preliminary results show no differences in outcome, but a significantly higher serious adverse event rate in the stent group (Dr. C.Y. Ponsioen, personal communication).

\section{Role of sphincterotomy}

\section{RECOMMENDATION}

9. ESGE/EASL recommend weighing the anticipated benefits of biliary papillotomy/sphincterotomy against its risks on a case-by-case basis.

Strong recommendation, moderate quality evidence. Biliary papillotomy/sphincterotomy should be considered especially after difficult cannulation

Strong recommendation, low quality evidence.

Biliary sphincterotomy was performed routinely as part of the endoscopic treatment of dominant stricture in some studies [46] while its use was restricted to specific cases such as stone extraction and difficulties in stent insertion in other studies. For example, in 32 PSC patients treated with stents for dominant stricture, sphincterotomy was performed in 12 patients (38\%) [36] while in another study of dominant stricture dilation with/without stenting, sphincterotomy was performed in $63 \%$ of 63 patients [44].

Generally, biliary sphincterotomy is not recommended as a routine procedure prior to biliary stenting because of the associated risks as demonstrated in randomized controlled trials (RCTs) [53]. However, if cannulation is difficult, biliary sphincterotomy is advised, bearing in mind that these patients are likely to require multiple procedures. Many endoscopists prefer a small sphincterotomy in PSC in order to avoid ascending cholangitis.

Specifically in PSC, biliary sphincterotomy was independently associated with an increased risk of short-term adverse 


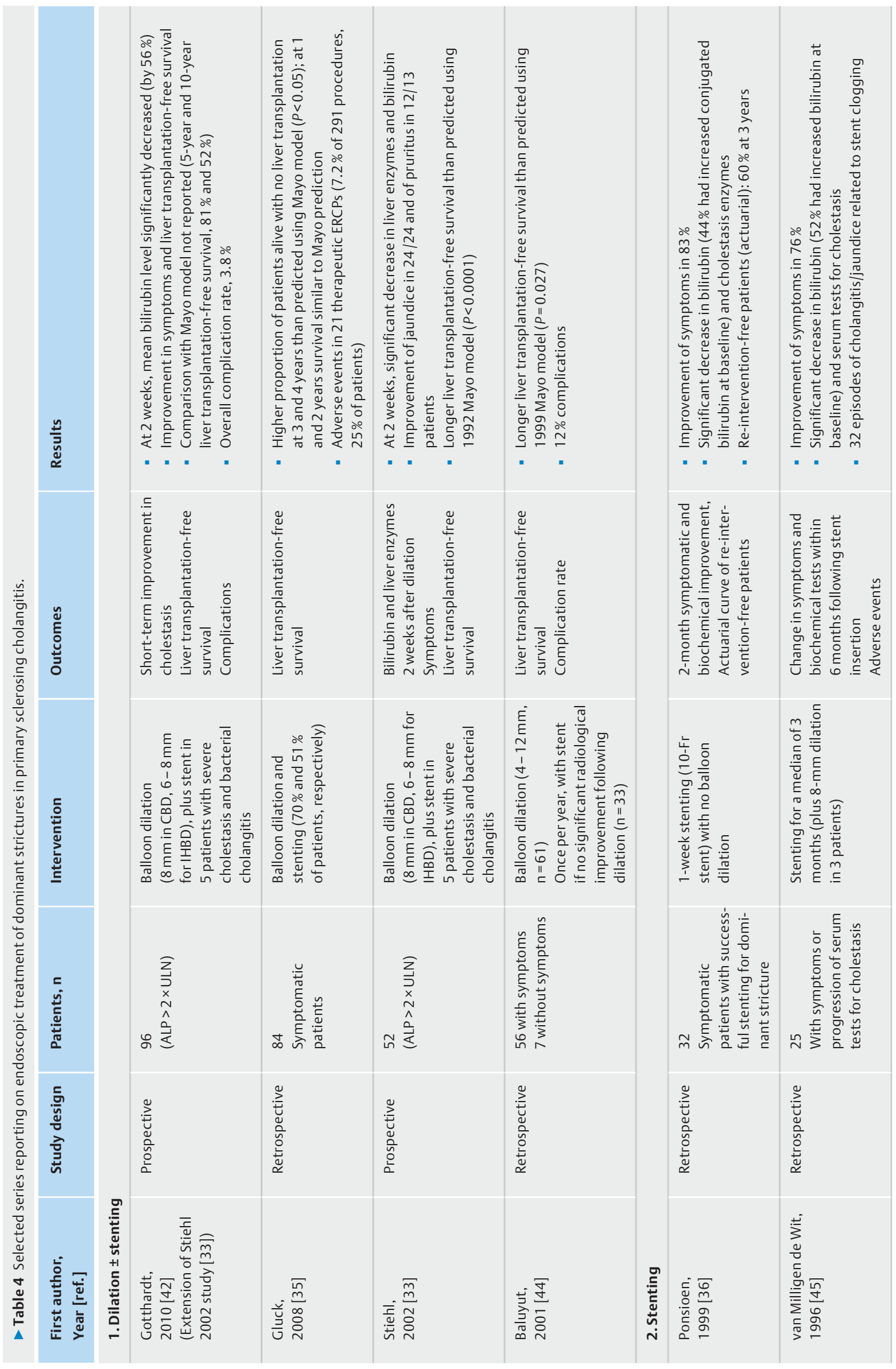




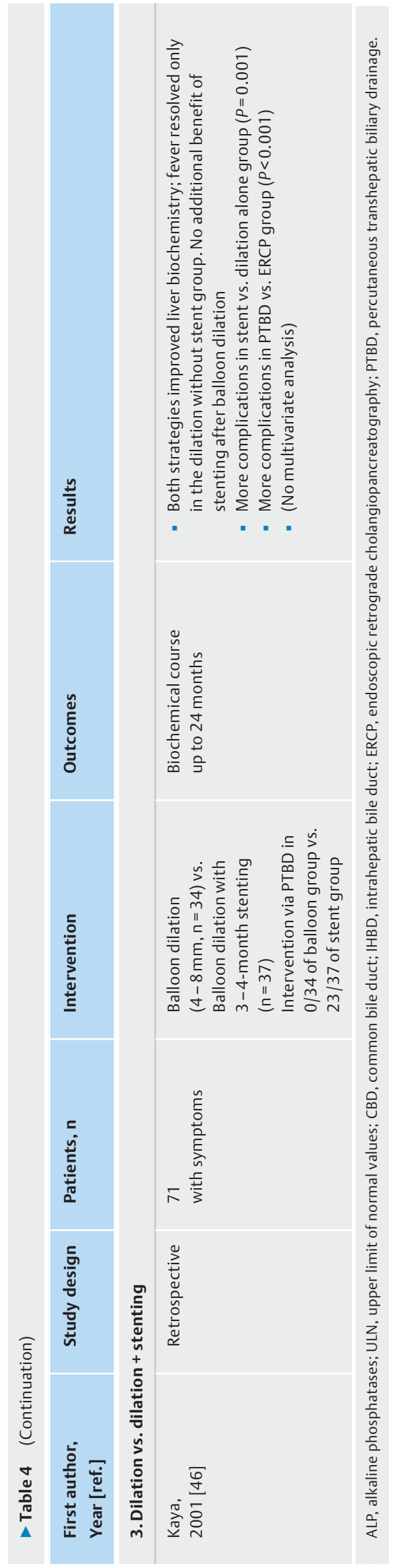

events in two retrospective studies (odds ratios [OR] 4.7 and $5.0)[54,55]$ while previous biliary papillotomy/sphincterotomy was protective for subsequent ERCPs [54]. Therefore experienced endoscopists perform biliary sphincterotomy in patients with difficult cannulation in whom ERCP is likely to be repeated during follow-up.

\section{Balloon dilation}

\section{RECOMMENDATION}

10. ESGE/EASL suggest selecting a balloon caliber of up to the maximum caliber of the ducts delimiting the stricture.

Weak recommendation, low quality evidence.

\section{RECOMMENDATION}

11.ESGE/EASL suggest repeating dilation of relapsing dominant stricture if: (i) the dominant stricture is regarded as the cause of recurrent symptoms (cholangitis, pruritus) or of significant increase in cholestasis; and (ii) the patient's response to previous dilations has been satisfactory.

Weak recommendation, very low quality evidence.

There are no comparative data on the optimal dilation scheme or balloon diameter for treating dominant strictures. In the largest prospective study (500 endoscopic balloon dilations in 96 patients), the authors performed stepwise dominant stricture dilation up to diameters of $8 \mathrm{~mm}$ and $6-8 \mathrm{~mm}$ in the common bile duct and the hepatic ducts, respectively [42]. Bile duct diameter upstream and downstream of the dominant stricture should be taken into account for selecting the balloon diameter to avoid dilating to more than the duct diameter. Balloon dilations are usually repeated at intervals of 1 to 4 weeks up to technical success, for an average of $2-3$ balloon dilations $[33,42,50]$. Technical success has been defined as complete balloon inflation within the dominant stricture with no waist observed fluoroscopically, followed by the unobstructed passage of contrast medium through the dilated biliary segment to the duodenum $[42,50]$. Using this technique, bile duct perforation was reported in $0.2 \%$ of dominant stricture dilations ( $1 \%$ of patients) [42]. In contrast, another study that used balloons of diameter 4-12 mm for dilation reported dilation-related biliary perforations in $3.5 \%$ of procedures [44].

Repeat balloon dilation during follow-up after initial treatment (usually consisting of several ERCPs) has been mentioned in some studies, but no results of the repeat dilation, in terms of clinical or biochemical improvement, have been reported $[33,50]$. 


\section{Stent therapy}

\section{RECOMMENDATION}

12. ESGE/EASL suggest selecting a single 10-Fr stent for dominant stricture in the extrahepatic ducts or two 7-Fr stents for hilar strictures extending into the left or right hepatic duct (final stent diameters in the case of stepwise stenting)

Weak recommendation, very low quality evidence.

In all large studies of endoscopic treatment for dominant stricture, plastic stents measuring 7 to $10 \mathrm{Fr}$ in diameter have been used, with no reported comparison of the results obtained with various stent diameters. Specifically, the Amsterdam group aimed at inserting a single $10-\mathrm{Fr}$ stent, and if this was not possible at first attempt, it was preceded by 1 -week stenting with a 7-Fr stent or insertion of a nasobiliary catheter [36, 56]. The Mayo group used 7-10-Fr stents at the endoscopist's discretion [46]. The Indianapolis group did not mention the diameter of stents used [44]. Two 7-Fr stents have typically been used in patients with multiple bilateral dominant strictures, and in patients with a hilar stricture extending into the left or right hepatic duct in order to avoid temporary obstruction of the contralateral biliary system. In general, the stent caliber and length must be adapted to the specific biliary tree configuration.

In other diseases, studies have shown that polyethylene stents provide better short-term (1-month) patency than Teflon models and that, in the long term, 10-Fr models provide longer biliary patency compared with thinner ones (11.5- $\mathrm{Fr}$ models do not provide longer patency) [53].

With respect to balloon dilation prior to stenting, it is currently unclear whether balloon dilation is beneficial before stent placement.

\section{Duration of stenting}

\section{RECOMMENDATION}

13. ESGE/EASL suggest that stents used for treating dominant stricture should be removed $1-2$ weeks following insertion.

Weak recommendation, low quality evidence.

No comparison of various stenting durations has been identified in studies reporting on stenting for dominant stricture. A short stenting duration is currently favored because stents tend to clog rapidly in PSC patients and similar efficacy results have been reported with short ( $1-2$ weeks) versus standard (8-12 weeks) stenting duration. Specifically, a retrospective study of short-term stenting (mean duration 11 days) in 32 symptomatic PSC patients with dominant stricture showed, at 2 months, a symptomatic improvement in $83 \%$ of the patients as well as a significant improvement of cholestasis test results; at 1 and 3 years, actuarial analysis showed that $80 \%$ and $60 \%$ of patients, respectively, would not require re-intervention [36]. Stent dysfunction was not reported in this study but two patients treated by stent removal developed hydrops of the gallbladder. The same group of authors had previously reported similar efficacy results with 3 -month stenting in 25 patients with symptomatic dominant stricture but, in that study, unscheduled stent exchange had to be performed on 32 occasions because of suspected stent clogging (cholangitis $n=23$, jaundice $n=9$ ) [45].

All studies mentioned focused on clinical and serum liver tests, not radiological data, to assess the short-term effect of therapeutic ERCP $[36,45,46,56]$. Endoscopic treatment has been repeated in a sizeable proportion of patients. For example, with long median stenting periods (3 months), the median number of repeated ERCPs per patient ranged between 3 and 5 during follow-up periods of 29 and 22 months in two studies $[45,46]$, while following a short stenting period (mean 11 days) repeat ERCP rates at 1 and 3 years after treatment were estimated at $20 \%$ and $40 \%$, respectively [36]. Other details about repeated treatments were not reported.

In many centers, stents are removed during an esophagogastroduodenoscopy without biliary opacification in PSC patients.

\section{Complications of endoscopic therapy}

\section{RECOMMENDATION}

14. ESGE/EASL suggest that ERCP in PSC patients should be undertaken by experienced pancreaticobiliary endoscopists.

Strong recommendation, very low quality evidence.

Several studies have evaluated the risk of complications in PSC patients undergoing ERCP [33, 35, 44, 49, 54, 55, 57 -62] ( $>$ Table 5). ERCP carries an increased risk for complications in the context of PSC, especially pancreatitis, cholangitis, and extravasation of contrast, although not all studies have documented such an increased risk in PSC $[59,62]$. In a systematic survey [63] of post-ERCP complications associated with various indications for ERCP, including 21 prospective studies and 16855 patients, the total complication rate was $6.85 \%$ (95\% Cl 6.46\%-7.24\%). Pancreatitis occurred in 585 patients (3.47\%, 95\% Cl 3.19\%-3.75\%). In another large retrospective single-center study [47], with 11497 procedures over 12 years, the total complication rate was $4.0 \%$ and pancreatitis occurred in $3.6 \%$. The overall risk of adverse events in patients with PSC has varied in different, much smaller studies, from $1.8 \%$ to $18.4 \%[33,35,44,49,55,57-62]$, which is higher than reported for other indications $[47,63]$.

Retraction of the papilla and an altered, more difficult position of the endoscope due to hypertrophy of the left liver lobe may be encountered during ERCP in PSC patients. Whether this actually influences cannulation success rates has not been investigated by specific studies. Cohort studies describing PSC patients provide only limited details on cannulation difficulties, with failure rates of $0 \%$ to $6 \%[33,36,41,49,50,57,62,64-$ 
- Table 5 Complications of endoscopic retrograde cholangiopancreatography (ERCP) in primary sclerosing cholangitis (PSC) patients.

\begin{tabular}{|c|c|c|c|c|c|}
\hline \multirow{2}{*}{$\begin{array}{l}\text { First author, } \\
\text { Year [ref] } \\
\text { Country }\end{array}$} & \multirow[t]{2}{*}{ Study design } & \multirow[t]{2}{*}{ Patients/ERCPs } & \multicolumn{3}{|c|}{ Complications, $\%$ of procedures } \\
\hline & & & Total & Pancreatitis & Cholangitis \\
\hline $\begin{array}{l}\text { Lee, } \\
1995 \text { [49] } \\
\text { USA }\end{array}$ & Retrospective & $53 / 175$ & 13.7 & 7 & 8 \\
\hline $\begin{array}{l}\text { van den Hazel, } \\
2000 \text { [57] } \\
\text { The Netherlands }\end{array}$ & Retrospective & $83 / 106$ & 9 & 3 & 2 \\
\hline $\begin{array}{l}\text { Baluyut, } \\
2001 \text { [44] } \\
\text { USA }\end{array}$ & Retrospective & $63 / 63$ & 1.8 & 1.26 & 0.6 \\
\hline $\begin{array}{l}\text { Stiehl, } \\
2002 \text { [33] } \\
\text { Germany }\end{array}$ & Retrospective & $\begin{array}{l}\text { 106/ERCP yearly, } \\
\text { median } 5 \text { years }\end{array}$ & 9 & 5.2 & 3.3 \\
\hline $\begin{array}{l}\text { Enns, } \\
2003 \text { [58] } \\
\text { Canada }\end{array}$ & Retrospective & 104 patients & 17 & 5 & 7.5 \\
\hline $\begin{array}{l}\text { Gluck, } \\
2008 \text { [35] } \\
\text { USA }\end{array}$ & Retrospective & $106 / 317$ & 7.3 & 3.8 & 0.95 \\
\hline $\begin{array}{l}\text { Etzel, } \\
2008 \text { [62] } \\
\text { USA }\end{array}$ & Retrospective & $\begin{array}{l}\text { PSC: } 30 / 85 \\
\text { Non-PSC: } 45 / 70\end{array}$ & $\begin{array}{r}12.9 \\
8.6\end{array}$ & $\begin{array}{l}2.4 \\
2.9\end{array}$ & $\begin{array}{l}5.9 \\
1.4\end{array}$ \\
\hline $\begin{array}{l}\text { Bangarulingam } \\
2009 \text { [59] } \\
\text { USA }\end{array}$ & Retrospective & $\begin{array}{l}\text { PSC: } 168 \\
\text { Non-PSC: } 981\end{array}$ & $\begin{array}{r}11 \\
8\end{array}$ & $\begin{array}{l}5 \\
4\end{array}$ & $\begin{array}{l}3.6 \\
0.2\end{array}$ \\
\hline $\begin{array}{l}\text { Alkhatib, } \\
2011[60] \\
\text { USA }\end{array}$ & Retrospective & $75 / 185$ & 8 & 5 & 1 \\
\hline $\begin{array}{l}\text { Ismail, } \\
2012 \text { [54] } \\
\text { Finland }\end{array}$ & Retrospective & $441 / 441$ & 9 & 7 & - \\
\hline $\begin{array}{l}\text { Navaneethan } \\
2015 \text { [55] } \\
\text { USA }\end{array}$ & Retrospective & $294 / 697$ & 4.3 & 1.2 & 2.4 \\
\hline $\begin{array}{l}\text { von Seth } \\
2015 \text { [61] } \\
\text { Sweden }\end{array}$ & $\begin{array}{l}\text { Retrospective, national } \\
\text { registry study }\end{array}$ & $\begin{array}{l}\text { PSC: } 141 / 141 \\
\text { Non-PSC: } 8791\end{array}$ & $\begin{array}{r}18.4 \\
7.3\end{array}$ & $\begin{array}{l}7.8 \\
3.2\end{array}$ & $\begin{array}{l}7.1 \\
2.1\end{array}$ \\
\hline
\end{tabular}

66]. Furthermore, there is likely a selection bias since most retrospective series describing the results of endoscopic treatment have the initiation of therapy as prerequisite, therefore potentially excluding cannulation failures.

The largest series is the study by Ismail et al. [54]. In this retrospective review of 441 ERCP procedures over a 3-year time period, primary cannulation success was $88.2 \%$. Of note, in 137 patients $(37.8 \%$ ) a previous biliary sphincterotomy had been performed. Pancreatic sphincterotomy as an access technique was used in $11.8 \%$ and freehand needle-knife sphincterotomy in a further $2.5 \%$. The primary failure rate was $0.5 \%$. These figures suggest that cannulation in PSC patients may indeed be more difficult than in other types of patients.

\section{Post-ERCP pancreatitis}

\section{RECOMMENDATION}

15. ESGE/EASL recommends routine rectal administration of $100 \mathrm{mg}$ of diclofenac or indomethacin immediately before or after ERCP in all patients without contraindication. In addition to this, in the case of high risk for post-ERCP pancreatitis, the placement of a 5-Fr prophylactic pancreatic stent should be considered.

Strong recommendation, high quality evidence. 
Post-ERCP pancreatitis (PEP) is the most common and feared complication associated with ERCP. The risk for PEP in PSC varies from $1 \%$ to $7 \%$, although the diagnostic criteria vary between studies [67]. Although the quality of the evidence is low, the factors increasing the risk for PEP are probably not different in PSC patients from those in the general population: female sex (OR 2.6, $P=0.015)$ and a guidewire in the pancreatic duct (OR 8.2, $P<0.01)$. Presence of a native papilla increases the risk whereas previous sphincterotomy decreases it [54], suggesting that pre-emptive endoscopic papillotomy might be warranted in PSC patients where repeat procedures might be anticipated. This has however yet to be proven.

Prolonged papilla contact time, as well as therapeutic procedures such as biliary brush cytology, sphincterotomy, stenting, and dilation, are associated with increased risk of PEP. Precut biliary and pancreatic sphincterotomy is markedly associated with PEP [54], possibly reflecting the difficult cannulation and prolonged procedure time. A recent Cochrane analysis comparing the contrast-assisted with the guidewire-assisted cannulation technique showed that the guidewire technique both increased the primary cannulation rate and reduced the risk of PEP, and it appears to be the most appropriate first-line cannulation technique [68].

Rectal nonsteroidal anti-inflammatory drugs (NSAIDs). In its 2014 update to a Guideline on the prophylaxis of PEP, ESGE recommends routine rectal administration of $100 \mathrm{mg}$ of diclofenac or indomethacin immediately before or after ERCP in all patients undergoing ERCP who were without contraindication to NSAIDs [69]. The recommendation was supported by the results of six meta-analyses published between 2009 and 2014 that compared NSAIDs versus placebo administration for prophylaxis of post-ERCP pancreatitis. These meta-analyses concordantly showed the benefit of NSAIDs in preventing either mild or moderate/severe PEP. These results were further supported by subsequent meta-analyses $[70,71]$ and the cost-efficiency of this approach has been demonstrated [72]. This recommendation applies to PSC patients.

Pancreatic stenting: The ESGE 2014 recommendation on prophylactic pancreatic stenting was supported by: (i) three meta-analyses of RCTs that showed a significant reduction in the incidence and the severity of PEP when prophylactic pancreatic stenting was used; and (ii) a study showing that pancreatic stent placement is cost-effective only in patients/procedures at high risk for post-ERCP pancreatitis.

The following conditions relevant to PSC are considered to represent high risk for PEP: precut biliary sphincterotomy, pancreatic guidewire-assisted biliary cannulation, endoscopic balloon sphincteroplasty, pancreatic sphincterotomy, and presence of more than three of the following risk factors: female gender, previous pancreatitis, younger age, nondilated extrahepatic bile ducts, absence of chronic pancreatitis, normal serum bilirubin, duration of cannulation attempts $>10 \mathrm{~min},>1$ pancreatic guidewire passage, pancreatic injection, failure to clear bile duct stones, intraductal ultrasound.

\section{RECOMMENDATION}

16. ESGE/EASL suggest routine administration of prophylactic antibiotics before ERCP in patients with PSC. Strong recommendation, low quality evidence.

Bacterial cholangitis and bacteriobilia are a not infrequent finding among patients with PSC. In studies evaluating the complications of ERCP in PSC the risk for cholangitis has varied from $0.25 \%$ to $8 \%[33,35,44,49,54,55,57-62]$ depending on, among other items, the criteria used to define cholangitis. The use of prophylactic antibiotics varies markedly between studies, in terms of prevalence, type of antibiotic, and duration of administration (from 1 oral dose before the procedure to 1 -week dosing afterwards). In a Cochrane meta-analysis (9 RCTs, 1573 patients), the prophylactic use of antibiotics was shown to prevent cholangitis (relative risk [RR] $0.54,95 \% \mathrm{Cl}$ $0.33-0.91$ ), septicemia (RR $0.35,95 \% \mathrm{Cl} 0.11-1.11$ ), bacteremia (RR $0.50,95 \% \mathrm{Cl} 0.33-0.78$ ), and pancreatitis (RR 0.54 , $95 \% \mathrm{Cl} 0.29-1.00)$. It was concluded that prophylactic antibiotics reduce bacteremia and seem to prevent cholangitis and septicemia in patients undergoing elective ERCP [73]. Our recommendation is in line with the American Society for Gastrointestinal Endoscopy (ASGE) recommendation to prescribe antibiotic prophylaxis in procedures where drainage achieved at ERCP is incomplete or achieved with difficulty, such as in PSC [74]. Bile fluid sampling could be considered during ERCP, to guide antibiotic treatment in case cholangitis occurs despite the prophylaxis [75].

\section{PSC and cholangiocarcinoma}

\section{RECOMMENDATION}

17.EASL/ESGE recommend that cholangiocarcinoma (CCA) should be suspected in any patient with worsening cholestasis, weight loss, raised serum CA19-9, and/or new or progressive dominant stricture, particularly with an associated enhancing mass lesion.

Strong recommendation, moderate quality evidence.

\section{RECOMMENDATION}

18. $A$ raised serum CA19-9 may support the diagnosis of CCA, but has a poor specificity.

Weak recommendation, low quality evidence.

PSC is associated with a markedly increased risk for CCA with a lifetime risk of $10 \%-20 \%$ [76, 77], or up to 400 -fold compared with the general population [78]. CCA represents a common cause of death among PSC patients [79], whereby $27 \%-50 \%$ of all CCAs are detected within 1 year of a PSC diagnosis $[41,78$, 80] depending on the indications for ERCP. 
CCA should be suspected in PSC patients experiencing rapid deterioration of liver function test findings, increasing jaundice, weight loss, and abdominal pain. However, the development of such a clinical trend may also suggest an advanced form of CCA. An observational study performed in the US on 230 patients affected by PSC, 23 of whom had CCA, showed no major differences in clinical features between patients without CCA and those with CCA at an earlier stage [40].

Increased serum CA19-9 levels have been reported to indicate the development of CCA in PSC patients. Cutoff levels of 129 or $100 \mathrm{U} / \mathrm{mL}$ detected CCA with high sensitivity (nearly $80 \%$ ) and specificity (nearly $100 \%$ ) [81], but only in advanced cases of CCA. These data are in contrast with other observations that showed that one third of PSC patients with high CA19-9 levels did not have CCA $[82,83]$. In a recent study performed on 433 PSC patients, 41 of whom had biliary malignancy, the use of FUT2/3 genotype-dependent cutoff values for CA19-9 improved sensitivity and reduced the number of falsepositive results [84]. In a study screening for biliary dysplasia using ERCP and brush cytology, serum CA19-9 had no prognostic value for biliary dysplasia or CCA [37].

Currently, there are no definite radiologic features that indicate CCA in a PSC patient, although the detection of a dominant stricture by MRC may be suggestive for CCA. However, $50 \%$ of PSC patients experience a dominant stricture and its absence does not rule out CCA. In a cohort of 230 patients, ultrasound, computed tomography (CT), and MRCP were found to have high specificity but low sensitivity $(10 \%-32 \%)$ [40].

\section{ERCP findings indicative of CCA}

Dominant strictures are frequent in PSC [42] and do not per se indicate development of a malignancy. In a large single-center study, CCA was seen in 6/95 dominant strictures (6\%). In general it could be inferred that the chance of any dominant stricture of harboring a CCA is around $5 \%$. Most CCAs develop in the perihilar region or in extrahepatic bile ducts, and are reachable with a cytological brush. In a large series of patients with CCA [85], 50\% had perihilar cancers, $42 \%$ had distal cancers, and only $8 \%$ were intrahepatic CCAs. No specific imaging features have been found to differentiate benign strictures from malignant ones. Based on ERCP findings only, it is not possible to exclude CCA from benign strictures caused by PSC, and the diagnosis always requires additional techniques such as imaging or biliary cytology or histology.

\section{RECOMMENDATION}

19. ESGE/EASL recommend ductal sampling (brush cytology, endobiliary biopsies) as part of the initial investigation for the diagnosis and staging of suspected CCA in patients with PSC.

Strong recommendation, high quality evidence.

\section{RECOMMENDATION}

20. ESGE/EASL suggest that fluorescence in situ hybridization (FISH) or equivalent chromosomal assessments are considered in patients with suspected CCA when brush cytology results are equivocal.

Weak recommendation, low quality evidence.

\section{RECOMMENDATION}

21.ESGE/EASL suggest that additional investigations such as cholangioscopy, endoscopic ultrasound, and probe-based confocal laser endomicroscopy (pCLE) may be useful in selected cases.

Weak recommendation, low quality evidence.

\section{Brush cytology}

Bile duct brushing is the most common method for tissue sampling in patients with PSC for detecting inflammation, biliary dysplasia or CCA ( $>$ Table $6, \triangleright$ Table 7 ). In a recent metaanalysis (11 studies, 747 patients) [95], the pooled diagnostic values of bile duct brushing for diagnosis of CCA in patients with PSC were: sensitivity $43 \%(95 \% \mathrm{Cl} 35 \%-52 \%)$, specificity $97 \%$ (95\%-98\%), PPV 78.2\% (63.6\%-86.7\%), and negative predictive value (NPV) $87.2 \%$ (85.4\%-89.1\%). The authors concluded that bile duct brushing is a simple and highly specific technique for detecting CCA in patients with PSC. However, the modest sensitivity from bile duct brushing precludes its utility as a diagnostic tool for early detection of CCA in patients with PSC. In a recent study of 261 mostly asymptomatic ( $81 \%$ ) patients with PSC, who had been referred for their first ERC to confirm the diagnosis and to screen for biliary dysplasia with systematic bile duct brushings, $43 \%$ were found to have advanced disease, and malignant/suspicious cytology was present in 6.9\% [37].

Addition of FISH analysis of cytology specimens enhanced the sensitivity for detecting CCA in patients with PSC in several patient series $[39,40,93,94]$. The ideal modality (e.g. FISH vs. digital image analysis vs. flow cytometry) and the appropriate threshold values for markers assessed by each of these modalities have not been robustly established, and this makes metaanalysis of available data challenging [96]. For this reason, chromosomal assessments can so far only be recommended in equivocal cases [96]. As DNA technologies evolve, new markers are likely to emerge.

\section{Ductal biopsy}

Ductal biopsy has been shown to improve sensitivity, specificity, and accuracy in diagnosing CCA compared to brush cytology alone [99]. Since the sampling area for ductal biopsies is limited, complementary biliary brushings should be considered in all patients. In published studies the sensitivity for the detection of CCA by ductal biopsy varies from $30 \%$ to $88 \%$ and the specificity from $97 \%$ to $100 \%$ [100]. Combined brush cytology 


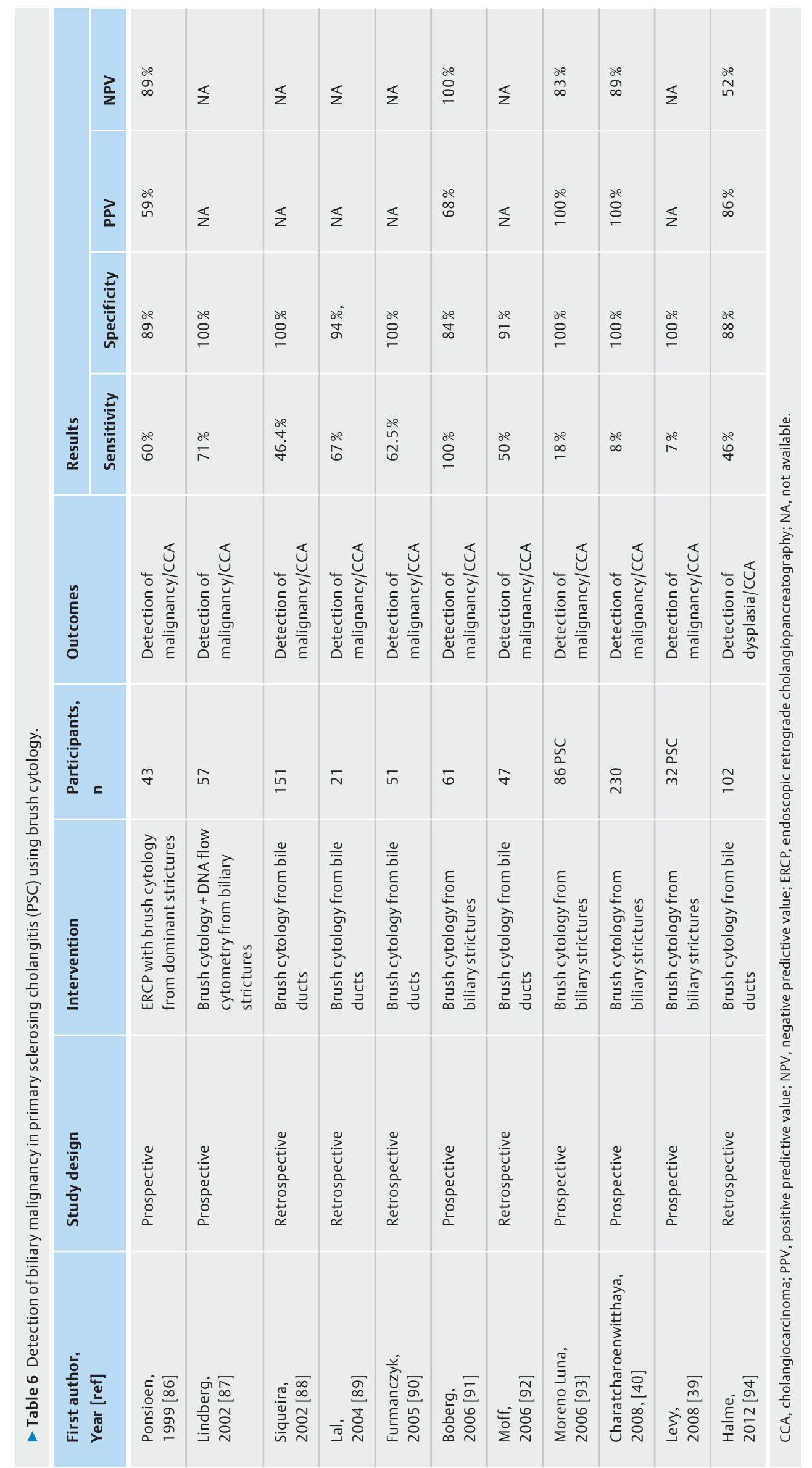




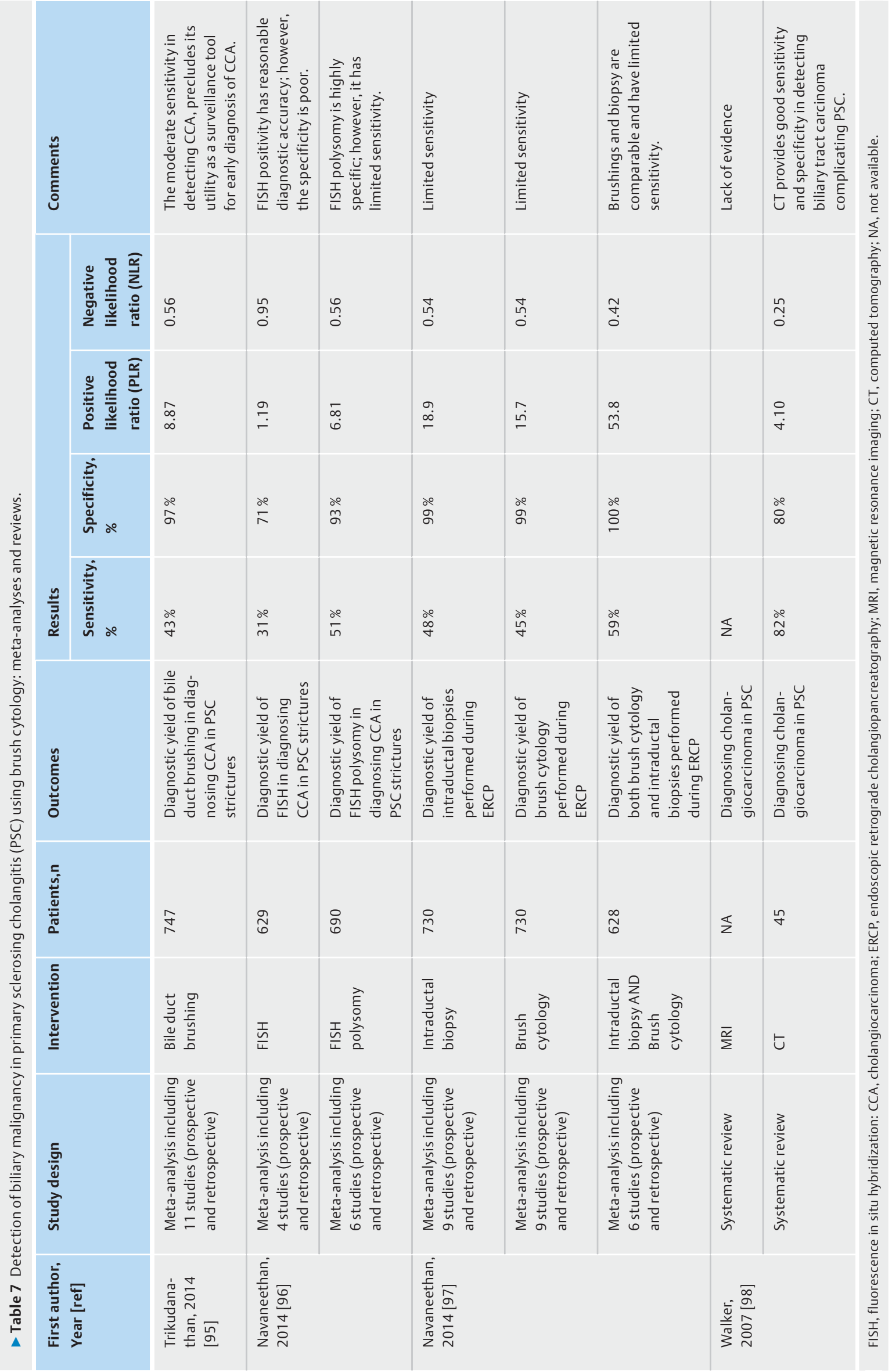


and biopsy has a sensitivity varying from $47 \%$ to $86 \%$ and specificity from $97 \%$ to $100 \%$. A retrospective study [100] assessed the accuracy of triple modality testing, namely brush cytology, biopsy, and FISH, and their combinations, in one patient group, and the accuracy of brush cytology alone in a separate patient group. It demonstrated that brush cytology alone had a sensitivity of $42 \%$, specificity $100 \%$, PPV $100 \%$, and NPV $88 \%$. The triple sample assessment modality markedly improved the overall sensitivity (82\%), with similar specificity (100\%), PPV (100\%), and NPV (87\%).

\section{Cholangioscopy}

Peroral cholangioscopy (POCS) allows direct visualization of extrahepatic bile duct strictures. The recent development of video-based systems provides better image resolution and offers clearer views than fiberoptic cholangioscopy. Compared to ERC and tissue sampling, POCS was shown to improve diagnostic accuracy [101-103]. However, these studies were not focused on CCA in PSC patients.

Single-operator cholangioscopy (SpyGlass) is gaining popularity, primarily for stone treatment and assessment of indeterminate strictures. Its utility in PSC was studied in a recent case series [104], with visual assessment and targeted biopsies of 64 strictures in 47 patients. Only 1 of 3 patients with CCA were diagnosed by the ERCP procedure. It is likely that newer digital versions of this instrument (e. g. SpyGlass DS) will perform better, at least in terms of visual diagnostics.

\section{Other techniques}

Other techniques such as intraductal ultrasonography and confocal laser endomicroscopy have shown potential utility in the diagnosis of CCA in PSC, but are not established in routine clinical practice. Regular endoscopic ultrasonography with sampling of detectable masses or locoregional lymph nodes is advocated by some, but such sampling is also regarded as a contraindication to liver transplantation in some centers; thus any such sampling should be discussed with local multidisciplinary teams.

\section{Endoscopic surveillance of PSC-associat- ed inflammatory bowel disease (IBD)}

The relationship between PSC and IBD is well established [105]. The prevalence of IBD in patients with established PSC varies widely, but is reported as $80 \%$ in Scandinavian countries [106]. The often asymptomatic phenotype of IBD means that prevalence data are strongly influenced by the level of proactive search for the disease. The typical scenario was for IBD to precede the presentation of PSC. However, the clinical presentation of IBD is variable, and the disease may be subclinical or asymptomatic for years [107] and is nowadays often diagnosed after the recognition of the liver disease. Notably, IBD may have been present for an unknown period of time when PSC is diagnosed. The increased risk of colon cancer in PSC-associated IBD $[108,109]$ hence makes it crucial to perform a full ileocolonoscopy at the time of PSC diagnosis in all patients. As to the diag- nosis of IBD per se, complete ileocolonoscopy is critical since rectal sparing, as well as right-sided involvement, is frequent in these patients [8].

\section{Timing of screening}

\section{RECOMMENDATION}

22. ESGE/EASL recommend screening ileocolonoscopy at the time of PSC diagnosis.

Strong recommendation, high quality evidence. If IBD is documented endoscopically or histologically, annual surveillance colonoscopies are warranted. Strong recommendation, low quality evidence.

\section{RECOMMENDATION}

23. ESGE/EASL suggest that if no IBD is documented, the next ileocolonoscopy should be considered at 5 years or whenever bowel complaints suggestive of IBD occur. Weak recommendation, low quality evidence.

Based on initial screening, subsequent surveillance can be planned. If IBD is documented, annual colonoscopies are warranted $[6,110]$ since it has been shown that PSC-IBD patients whose colorectal cancer (CRC) is detected in a surveillance program have a significantly lower risk of CRC-related mortality as compared to non-surveilled patients [78]. If not, repeat colonoscopy should be done with the occurrence of symptoms suggestive of IBD, or of elevated F-calprotectin, or otherwise at 3 5 years [111], although this recommendation lacks any scientific evidence beyond extrapolation from general IBD recommendations [112].

\section{Endoscopic modality}

\section{RECOMMENDATION}

24. For screening for the presence of IBD, EASL/ESGE recommend ileocolonoscopy with four-quadrant biopsies from all colonic segments and the terminal ileum. Strong recommendation, low quality evidence.

\section{RECOMMENDATION}

25.For dysplasia surveillance of PSC-associated IBD, EASL/ESGE recommend ileocolonoscopy with dye-based chromoendoscopy with targeted biopsies.

Strong recommendation, low quality evidence.

PSC-associated colitis seems to be distinctive from other IBD: colitis is predominant in the right colon [113] and colon cancer is typically right-sided [114]. Lack of inflammation in the rectum ("rectal sparing") is reported in some studies but less frequently observed in others [3]. Endoscopic surveillance 
of PSC-associated colitis is presumed to increase the chance of early detection of dysplasia or malignancy [115].

Screening for IBD at diagnosis of PSC is best performed by high definition ileocolonoscopy with four-quadrant biopsies from all colonic segments and the terminal ileum. Biopsies should be taken at the index endoscopy even without macroscopic signs of inflammation [111,116,117].

In established PSC-IBD, ileocolonoscopy with dye-based chromoendoscopy $(0.1 \%$ methylene blue or $0.1 \%-0.5 \%$ indigo carmine) with targeted biopsies is required for neoplasia surveillance of PSC-associated IBD. In appropriately trained hands, in the situation of quiescent disease activity and adequate bowel preparation, nontargeted four-quadrant biopsies can be abandoned [118]. This approach is also endorsed by the European Crohn's and Colitis Organisation (ECCO) [112]. It should be noted that there are no studies on colonic neoplasia surveillance specifically in the setting of PSC-associated IBD.

Routine use of pancolonic chromoendoscopy with targeted biopsies for neoplasia surveillance in patients with long-standing colitis (disease duration of $>8$ years) increased the proportion of patients found with dysplasia by a factor of $2.1-3.3$ compared to standard definition videocolonoscopy. For the detection of patients with neoplasia, the pooled incremental yield of conventional chromoendoscopy with random biopsies over standard white-light endoscopy with random biopsies was $7 \%$ (95\% Cl 3.2\%-11.3\%) [119]. The benefit of conventional chromoendoscopy over white-light endoscopy with latest-generation high definition colonoscopes is unknown to date.

\section{Handling of polyps and colorectal dysplasia}

\section{RECOMMENDATION}

26.ESGE/EASL recommend endoscopic resection of any visible lesions and assessment of the surrounding mucosa. We recommend proctocolectomy in the case of dysplasia in the surrounding mucosa, or when the lesion cannot be completely resected. Otherwise, repeat colonoscopy and close follow-up is warranted.

Strong recommendation, low quality evidence.

\section{RECOMMENDATION}

27. In the case of invisible lesions with high grade dysplasia (HGD) confirmed by two expert pathologists, proctocolectomy should be advised

Strong recommendation, low quality evidence.

\section{RECOMMENDATION}

28. In the case of invisible lesions with low grade dysplasia (LGD) confirmed by two expert pathologists, repeat colonoscopy after 3 months with chromoendoscopy is recommended.

Strong recommendation, low quality evidence.
Colorectal cancer (CRC) risk is significantly increased in patients with coexisting IBD and PSC. A meta-analysis of 11 studies concluded that patients with ulcerative colitis and PSC were at increased risk of developing CRC compared to patients with ulcerative colitis alone (OR 4.09; 95\%Cl 2.89-5.76) [109]. A recent large population-based study in the Netherlands found a 9-fold increased risk of developing CRC in PSC-ulcerative colitis patients, compared to the age- and gender-matched population (standardized incidence ratio [SIR] 8.6, 95\%Cl 3.5-17.7), and a 10 -fold increased risk, compared to ulcerative colitis controls (ratio of SIRs 9.8, 95\%Cl 1.9-96.6) [78].

Most dysplasia is visible at colonoscopy $[120,121]$. On the other hand, invisible dysplastic lesions can also be diagnosed by random biopsies during surveillance. According to the IBD Dysplasia Morphology Study Group [122], dysplasia is subdivided into LGD and HGD.

Recent ECCO guidelines state that a visible lesion with dysplasia should be completely resected endoscopically irrespective of the grade of dysplasia or the location relative to the inflamed mucosal areas [112]. Subsequently, the surrounding mucosa (around the visible lesion) should be examined (with chromoendoscopy-guided targeted biopsies or random biopsies if chromoendoscopy is not available). If endoscopic resection is incomplete or impossible, or if dysplasia is detected in the surrounding mucosa, total proctocolectomy is recommended.

In the case of invisible lesions with LGD, urgent repeat chromoendoscopy should be performed, to eventually identify a well-circumscribed lesion and/or perform additional random biopsies. If the presence of LGD is confirmed, there is no clear consensus regarding management; proctocolectomy or surveillance could be recommended. Actually, two studies revealed a significant 5-year progression rate (33\% - 54\%) of LGD to $\operatorname{HGD}[123,124]$, whereas others showed low progression rates $[125,126]$. Finally, in the case of invisible lesions with HGD or adenocarcinoma, total proctocolectomy is indicated.

This Guideline from ESGE and EASL represents a consensus of best practice based on the available evidence at the time of preparation. The recommendations might not apply in all situations and should be interpreted in the light of specific clinical situations and resource availability. Further controlled clinical studies may be needed to clarify aspects of the Guideline, and revision may be necessary as new data appear. Clinical considerations may justify a course of action at variance to these recommendations. This ESGE/EASL Guideline is intended to be an educational device to provide information that may assist endoscopists in providing care to patients. It is not a set of rules and should not be construed as establishing a legal standard of care or as encouraging, advocating, requiring, or discouraging any particular treatment. 
J. Albert has received (from 2015 to 2016) speaker's honoraria from Fujifilm, the Falk Foundation, Covidien/Medtronic, and Olympus Europe, an honorarium from Covidien/Medtronic for advisory services, and research support from Olympus Europe. P. Fickert has served on advisory boards for Dr. Falk Pharma and Intercept; his department has received unrestricted research grants from the Falk Foundation (since 2010) and Gilead (since 2012); he is listed as co-inventor in two patents filed by the Medical University of Graz for the use of norUDCA in the treatment of liver diseases and arteriosclerosis (publication numbers WO2006119803 and WO20099013334). A. Laghi has received a speaker fee from GE Healthcare (October 2016). J.-W. Poley receives consultancy, travel, and speaker fees from Cook Endoscopy; his department receives financial support for consultancy, travel, and speaking from Boston Scientific; he receives travel and consultancy fees from Pentax. C. Ponsioen's department is receiving research support from Olympus and Fujifilm. C. Schramm has served on an advisory board for Intercept Pharmaceuticals (2016), and has given lectures sponsored by Intercept and the Falk Foundation. F. Swahn has served on a scientific advisory board for Rhenman \& Partners, and has given lectures sponsored by Cook Medical Sweden and Boston Scientific Nordic. L. Aabakken, M. Arvanitakis, O. Chazouilleres, J.-M. Dumonceau, M. Färrkkilä, C. Hassan, G. Hirschfield, T. Karlsen, M. Marzioni, M. Fernandez, S. Pereira, J. Pohl, and A. Tringali have no competing interests.

\section{References}

[1] Olsson R, Danielsson A, Jarnerot G et al. Prevalence of primary sclerosing cholangitis in patients with ulcerative colitis. Gastroenterology 1991; 100: 1319-1323

[2] Lunder AK, Hov JR, Borthne A et al. Prevalence of sclerosing cholangitis, detected by magnetic resonance cholangiography, in patients with long-term inflammatory bowel disease. Gastroenterology 2016; 151: 660 - 669.e4

[3] Boonstra K, van Erpecum KJ, van Nieuwkerk KM et al. Primary sclerosing cholangitis is associated with a distinct phenotype of inflammatory bowel disease. Inflamm Bowel Dis 2012; 18: 2270 - 2276

[4] O’Toole A, Alakkari A, Keegan D et al. Primary sclerosing cholangitis and disease distribution in inflammatory bowel disease. Clin Gastroenterol Hepatol 2012; 10: 439-441

[5] Loftus EV Jr., Harewood GC, Loftus CG et al. PSC-IBD: a unique form of inflammatory bowel disease associated with primary sclerosing cholangitis. Gut 2005; 54: 91 - 96

[6] EASL Clinical Practice Guidelines: management of cholestatic liver diseases. J Hepatol 2009; 51: 237-267

[7] Atkins D, Eccles M, Flottorp S et al. Systems for grading the quality of evidence and the strength of recommendations I: critical appraisal of existing approaches The GRADE Working Group. BMC Health Serv Res 2004; 4: 38

[8] Chapman R, Fevery J, Kalloo A et al. Diagnosis and management of primary sclerosing cholangitis. Hepatology 2010; 51: 660-678

[9] Berstad AE, Aabakken L, Smith H] et al. Diagnostic accuracy of magnetic resonance and endoscopic retrograde cholangiography in pri- mary sclerosing cholangitis. Clin Gastroenterol Hepatol 2006; 4: $514-520$

[10] Moff SL, Kamel IR, Eustace J et al. Diagnosis of primary sclerosing cholangitis: a blinded comparative study using magnetic resonance cholangiography and endoscopic retrograde cholangiography. Gastrointest Endosc 2006; 64: $219-223$

[11] Philpott C, Rosenbaum J, Moon A et al. Paediatric MRCP: 10 year experience with 195 patients. Eur J Radiol 2013; 82: 699-706

[12] Rossi G, Sciveres M, Maruzzelli L et al. Diagnosis of sclerosing cholangitis in children: blinded, comparative study of magnetic resonance versus endoscopic cholangiography. Clin Res Hepatol Gastroenterol 2013; 37: $596-601$

[13] Dave M, Elmunzer BJ, Dwamena BA et al. Primary sclerosing cholangitis: meta-analysis of diagnostic performance of MR cholangiopancreatography. Radiology 2010; 256: 387 - 396

[14] Meagher S, Yusoff I, Kennedy W et al. The roles of magnetic resonance and endoscopic retrograde cholangiopancreatography (MRCP and ERCP) in the diagnosis of patients with suspected sclerosing cholangitis: a cost-effectiveness analysis. Endoscopy 2007; 39: 222 - 228

[15] Talwalkar JA, Angulo P, Johnson CD et al. Cost-minimization analysis of MRC versus ERCP for the diagnosis of primary sclerosing cholangitis. Hepatology 2004; 40: 39-45

[16] Kalaitzakis E, Levy M, Kamisawa T et al. Endoscopic retrograde cholangiography does not reliably distinguish IgG4-associated cholangitis from primary sclerosing cholangitis or cholangiocarcinoma. Clin Gastroenterol Hepatol 2011; 9: 800-803 e2

[17] Ruiz A, Lemoinne S, Carrat F et al. Radiologic course of primary sclerosing cholangitis: assessment by three-dimensional magnetic resonance cholangiography and predictive features of progression. Hepatology 2014; 59: $242-250$

[18] Weber C, Kuhlencordt R, Grotelueschen R et al. Magnetic resonance cholangiopancreatography in the diagnosis of primary sclerosing cholangitis. Endoscopy 2008; 40: 739-745

[19] Eaton JE, Talwalkar JA, Lazaridis KN et al. Pathogenesis of primary sclerosing cholangitis and advances in diagnosis and management. Gastroenterology 2013; 145: 521 - 536

[20] Li-Yeng C, Goldberg HI. Sclerosing cholangitis: broad spectrum of radiographic features. Gastrointest Radiol 1984; 9: 39-47

[21] Majoie CB, Reeders JW, Sanders JB et al. Primary sclerosing cholangitis: a modified classification of cholangiographic findings. AJR Am J Roentgenol 1991; 157: 495-497

[22] Ponsioen CY, Vrouenraets SM, Prawirodirdjo W et al. Natural history of primary sclerosing cholangitis and prognostic value of cholangiography in a Dutch population. Gut 2002; 51: $562-566$

[23] Ponsioen CY, Reitsma JB, Boberg KM et al. Validation of a cholangiographic prognostic model in primary sclerosing cholangitis. Endoscopy 2010; 42: $742-747$

[24] Craig DA, MacCarty RL, Wiesner RH et al. Primary sclerosing cholangitis: value of cholangiography in determining the prognosis. AJR Am J Roentgenol 1991; 157: 959-964

[25] Abdalian R, Heathcote EJ. Sclerosing cholangitis: a focus on secondary causes. Hepatology 2006; 44: 1063 - 1074

[26] Trauner M, Fickert P, Wagner M. MDR3 (ABCB4) defects: a paradigm for the genetics of adult cholestatic syndromes. Semin Liver Dis 2007 . 27: $77-98$

[27] Mesenas S, Vu C, Doig L et al. Duodenal EUS to identify thickening of the extrahepatic biliary tree wall in primary sclerosing cholangitis. Gastrointest Endosc 2006; 63: $403-408$

[28] Rustemovic N, Cukovic-Cavka S, Opacic M et al. Endoscopic ultrasound elastography as a method for screening the patients with suspected primary sclerosing cholangitis. Eur ] Gastroenterol Hepatol $2010 ; 22: 748-753$ 
[29] Lutz HH, Wasmuth HE, Streetz K et al. Endoscopic ultrasound as an early diagnostic tool for primary sclerosing cholangitis: a prospective pilot study. Endoscopy 2012; 44: $934-939$

[30] EASL-ALEH Clinical Practice Guidelines: Non-invasive tests for evaluation of liver disease severity and prognosis. J Hepatol 2015; 63: 237 264

[31] Cotton PB, Nickl N. Endoscopic and radiologic approaches to therapy in primary sclerosing cholangitis. Semin Liver Dis 1991; 11: 40 - 48

[32] Johnson GK, Geenen JE, Venu RP et al. Endoscopic treatment of biliary tract strictures in sclerosing cholangitis: a larger series and recommendations for treatment. Gastrointest Endosc 1991; 37: 38 - 43

[33] Stiehl A, Rudolph G, Klöters-Plachky P et al. Development of dominant bile duct stenoses in patients with primary sclerosing cholangitis treated with ursodeoxycholic acid: outcome after endoscopic treatment. J Hepatol 2002; 36: 151 - 156

[34] Bjornsson E, Lindqvist-Ottosson J, Asztely M et al. Dominant strictures in patients with primary sclerosing cholangitis. Am J Gastroenterol 2004; 99: 502-508

[35] Gluck M, Cantone NR, Brandabur J] et al. A twenty-year experience with endoscopic therapy for symptomatic primary sclerosing cholangitis. J Clin Gastroenterol 2008; 42: 1032-1039

[36] Ponsioen CY, Lam K, van Milligen de Wit AW et al. Four years experience with short term stenting in primary sclerosing cholangitis. Am J Gastroenterol 1999; 94: 2403-2407

[37] Boyd S, Tenca A, Jokelainen K et al. Screening primary sclerosing cholangitis and biliary dysplasia with endoscopic retrograde cholangiography and brush cytology: risk factors for biliary neoplasia. Endoscopy 2016; 48: 432-439

[38] Aljiffry M, Renfrew PD, Walsh MJ et al. Analytical review of diagnosis and treatment strategies for dominant bile duct strictures in patients with primary sclerosing cholangitis. HPB (Oxford) 2011; 13: 79-90

[39] Levy MJ, Baron TH, Clayton AC et al. Prospective evaluation of advanced molecular markers and imaging techniques in patients with indeterminate bile duct strictures. Am J Gastroenterol 2008; 103: $1263-1273$

[40] Charatcharoenwitthaya P, Enders FB, Halling KC et al. Utility of serum tumor markers, imaging, and biliary cytology for detecting cholangiocarcinoma in primary sclerosing cholangitis. Hepatology 2008; 48: $1106-1117$

[41] Chapman MH, Webster G], Bannoo S et al. Cholangiocarcinoma and dominant strictures in patients with primary sclerosing cholangitis: a 25-year single-centre experience. Eur J Gastroenterol Hepatol 2012; 24: $1051-1058$

[42] Gotthardt DN, Rudolph G, Kloters-Plachky P et al. Endoscopic dilation of dominant stenoses in primary sclerosing cholangitis: outcome after long-term treatment. Gastrointest Endosc 2010; 71: 527-534

[43] Kaltenthaler E, Vergel YB, Chilcott J et al. A systematic review and economic evaluation of magnetic resonance cholangiopancreatography compared with diagnostic endoscopic retrograde cholangiopancreatography. Health Technol Assess 2004; 8: iii: 1-89

[44] Baluyut AR, Sherman S, Lehman GA et al. Impact of endoscopic therapy on the survival of patients with primary sclerosing cholangitis. Gastrointest Endosc 2001; 53: 308-312

[45] van Milligen de Wit AW, van Bracht J, Rauws EA et al. Endoscopic stent therapy for dominant extrahepatic bile duct strictures in primary sclerosing cholangitis. Gastrointest Endosc 1996; 44: 293 -299

[46] Kaya M, Petersen BT, Angulo P et al. Balloon dilation compared to stenting of dominant strictures in primary sclerosing cholangitis. Am J Gastroenterol 2001; 96: 1059-1066

[47] Cotton PB, Garrow DA, Gallagher J et al. Risk factors for complications after ERCP: a multivariate analysis of 11,497 procedures over 12 years. Gastrointest Endosc 2009; 70: $80-88$
[48] Johnson GK, Saeian K, Geenen JE. Primary sclerosing cholangitis treated by endoscopic biliary dilation: review and long-term followup evaluation. Curr Gastroenterol Rep 2006; 8: 147-155

[49] Lee JG, Schutz SM, England RE et al. Endoscopic therapy of sclerosing cholangitis. Hepatology 1995; 21: 661-667

[50] Wagner S, Gebel M, Meier P et al. Endoscopic management of biliary tract strictures in primary sclerosing cholangitis. Endoscopy 1996; 28: $546-551$

[51] Ahrendt SA, Pitt HA, Kalloo AN et al. Primary sclerosing cholangitis: resect, dilate, or transplant? Ann Surg 1998; 227: 412 - 423

[52] Beuers U, Spengler U, Sackmann M et al. Deterioration of cholestasis after endoscopic retrograde cholangiography in advanced primary sclerosing cholangitis. J Hepatol 1992; 15: $140-143$

[53] Dumonceau JM, Tringali A, Blero D et al. Biliary stenting: indications, choice of stents and results: European Society of Gastrointest Endosc (ESGE) clinical guideline. Endoscopy 2012; 44: 277-292

[54] Ismail S, Kylänpää L, Mustonen $\mathrm{H}$ et al. Risk factors for complications of ERCP in primary sclerosing cholangitis. Endoscopy 2012; 44: $1133-1138$

[55] Navaneethan U, Jegadeesan R, Nayak S et al. ERCP-related adverse events in patients with primary sclerosing cholangitis. Gastrointest Endosc 2015; 81: 410-419

[56] van Milligen de Wit AW, Rauws EA, van Bracht J et al. Lack of complications following short-term stent therapy for extrahepatic bile duct strictures in primary sclerosing cholangitis. Gastrointest Endosc 1997; 46: $344-347$

[57] van den Hazel SJ, Wolfhagen EH, van Buuren HR et al. Prospective risk assessment of endoscopic retrograde cholangiography in patients with primary sclerosing cholangitis. Dutch PSC Study Group. Endoscopy 2000; 32: 779-782

[58] Enns R, Eloubeidi MA, Mergener $\mathrm{K}$ et al. Predictors of successful clinical and laboratory outcomes in patients with primary sclerosing cholangitis undergoing endoscopic retrograde cholangiopancreatography. Can J Gastroenterol 2003; 17: 243-248

[59] Bangarulingam SY, Gossard AA, Petersen BT et al. Complications of endoscopic retrograde cholangiopancreatography in primary sclerosing cholangitis. Am J Gastroenterol 2009; 104: 855-860

[60] Alkhatib AA, Hilden K, Adler DG. Comorbidities, sphincterotomy, and balloon dilation predict post-ERCP adverse events in PSC patients: operator experience is protective. Dig Dis Sci 2011; 56: 3685-3688

[61] von Seth E, Arnelo U, Enochsson L et al. Primary sclerosing cholangitis increases the risk for pancreatitis after endoscopic retrograde cholangiopancreatography. Liver Int 2015; 35: 254-262

[62] Etzel JP, Eng SC, Ko CW et al. Complications after ERCP in patients with primary sclerosing cholangitis. Gastrointest Endosc 2008; 67: 643 648

[63] Andriulli A, Loperfido S, Napolitano G et al. Incidence rates of postERCP complications: a systematic survey of prospective studies. Am J Gastroenterol 2007; 102: 1781-1788

[64] Lombard M, Farrant M, Karani J et al. Improving biliary-enteric drainage in primary sclerosing cholangitis: experience with endoscopic methods. Gut 1991; 32: $1364-1368$

[65] Stiehl A, Rudolph G, Sauer P et al. Efficacy of ursodeoxycholic acid treatment and endoscopic dilation of major duct stenoses in primary sclerosing cholangitis. An 8-year prospective study. J Hepatol 1997; 26: $560-566$

[66] Linder S, Soderlund C. Endoscopic therapy in primary sclerosing cholangitis: outcome of treatment and risk of cancer. Hepatogastroenterology 2001; 48: 387-392

[67] Moreno Luna LE, Gores G]. Advances in the diagnosis of cholangiocarcinoma in patients with primary sclerosing cholangitis. Liver Transpl 2006; 12 : (Suppl. 02): S15-19 
[68] Tse F, Yuan Y, Moayyedi P et al. Guidewire-assisted cannulation of the common bile duct for the prevention of post-endoscopic retrograde cholangiopancreatography (ERCP) pancreatitis. Cochrane Database Syst Rev Dec 2012: DOI: 10.1002/14651858.CD009662.pub2

[69] Dumonceau JM, Andriulli A, Elmunzer B] et al. Prophylaxis of postERCP pancreatitis: European Society of Gastrointest EndosC (ESGE) Guideline - updated June 2014. Endoscopy 2014; 46: 799-815

[70] Shi N, Deng L, Altaf K et al. Rectal indomethacin for the prevention of post-ERCP pancreatitis: A meta-analysis of randomized controlled trials. Turk J Gastroenterol 2015; 26: 236-240

[71] Andrade-Davila VF, Chavez-Tostado M, Davalos-Cobian C et al. Rectal indomethacin versus placebo to reduce the incidence of pancreatitis after endoscopic retrograde cholangiopancreatography: results of a controlled clinical trial. BMC Gastroenterol 2015; 15: 85

[72] Nicolas-Perez D, Castilla-Rodriguez I, Gimeno-Garcia AZ et al. Prevention of post-endoscopic retrograde cholangiopancreatography pancreatitis: a cost-effectiveness analysis. Pancreas 2015; 44: 204 210

[73] Brand M, Bizos D, O'Farrell P Jr. Antibiotic prophylaxis for patients undergoing elective endoscopic retrograde cholangiopancreatography. Cochrane Database Syst Rev 2010: DOI: 10.1002/14651858. CD007345.pub2

[74] Khashab MA, Chithadi KV, Acosta RD et al. Antibiotic prophylaxis for Gl endoscopy. Gastrointest Endosc 2015; 81: $81-89$

[75] Negm AA, Schott A, Vonberg RP et al. Routine bile collection for microbiological analysis during cholangiography and its impact on the management of cholangitis. Gastrointest Endosc 2010; 72: 284-291

[76] Razumilava N, Gores G], Lindor KD. Cancer surveillance in patients with primary sclerosing cholangitis. Hepatology 2011; 54: $1842-$ 1852

[77] Weismüller TJ, Trivedi PJ, Bergquist A et al. Patient Age, Sex, and Inflammatory Bowel Disease Phenotype Associate With Course of Primary Sclerosing Cholangitis. Gastroenterology 2017: Mar 5. pii: S0016-5085(17)30236-6 DOI: 10.1053/j.gastro.2017.02.038 [Epub ahead of print]

[78] Boonstra K, Weersma RK, van Erpecum KJ et al. Population-based epidemiology, malignancy risk, and outcome of primary sclerosing cholangitis. Hepatology 2013; 58: 2045-2055

[79] de Valle MB, Bjornsson E, Lindkvist B. Mortality and cancer risk related to primary sclerosing cholangitis in a Swedish population-based cohort. Liver Int 2012; 32: 441 - 448

[80] Boberg KM, Bergquist A, Mitchell S et al. Cholangiocarcinoma in primary sclerosing cholangitis: risk factors and clinical presentation. Scand J Gastroenterol 2002; 37: 1205-1211

[81] Levy C, Lymp J, Angulo P et al. The value of serum CA 19-9 in predicting cholangiocarcinomas in patients with primary sclerosing cholangitis. Dig Dis Sci 2005; 50: 1734 - 1740

[82] Sinakos E, Saenger AK, Keach J et al. Many patients with primary sclerosing cholangitis and increased serum levels of carbohydrate antigen 19-9 do not have cholangiocarcinoma. Clin Gastroenterol Hepatol 2011; 9: 434-439e1

[83] Venkatesh PG, Navaneethan U, Shen B et al. Increased serum levels of carbohydrate antigen 19-9 and outcomes in primary sclerosing cholangitis patients without cholangiocarcinoma. Dig Dis Sci 2013; 58: $850-857$

[84] Wannhoff A, Hov JR, Folseraas T et al. FUT2 and FUT3 genotype determines CA19-9 cut-off values for detection of cholangiocarcinoma in patients with primary sclerosing cholangitis. J Hepatol 2013; 59: $1278-1284$

[85] DeOliveira ML, Cunningham SC, Cameron JL et al. Cholangiocarcinoma: thirty-one-year experience with 564 patients at a single institution. Ann Surg 2007; 245: 755 - 762
[86] Ponsioen CY, Vrouenraets SM, van Milligen de Wit AW et al. Value of brush cytology for dominant strictures in primary sclerosing cholangitis. Endoscopy 1999; 31: 305-309

[87] Lindberg B, Arnelo U, Bergquist A et al. Diagnosis of biliary strictures in conjunction with endoscopic retrograde cholangiopancreaticography, with special reference to patients with primary sclerosing cholangitis. Endoscopy 2002; 34: 909-916

[88] Siqueira E, Schoen RE, Silverman W et al. Detecting cholangiocarcinoma in patients with primary sclerosing cholangitis. Gastrointest Endosc 2002; 56: $40-47$

[89] Lal A, Okonkwo A, Schindler S et al. Role of biliary brush cytology in primary sclerosing cholangitis. Acta Cytol 2004; 48: 9-12

[90] Furmanczyk PS, Grieco VS, Agoff SN. Biliary brush cytology and the detection of cholangiocarcinoma in primary sclerosing cholangitis: evaluation of specific cytomorphologic features and CA19-9 levels. Am J Clin Pathol 2005; 124: 355 - 360

[91] Boberg KM, Jebsen P, Clausen OP et al. Diagnostic benefit of biliary brush cytology in cholangiocarcinoma in primary sclerosing cholangitis. J Hepatol 2006; 45: 568-574

[92] Moff SL, Clark DP, Maitra A et al. Utility of bile duct brushings for the early detection of cholangiocarcinoma in patients with primary sclerosing cholangitis. J Clin Gastroenterol 2006; 40: 336-341

[93] Moreno Luna LE, Kipp B, Halling KC et al. Advanced cytologic techniques for the detection of malignant pancreatobiliary strictures. Gastroenterology 2006; 131: 1064-1072

[94] Halme L, Arola J, Numminen K et al. M. Biliary dysplasia in patients with primary sclerosing cholangitis: additional value of DNA ploidity. Liver Int 2012; 32: 783 - 789

[95] Trikudanathan G, Navaneethan U, Njei B et al. Diagnostic yield of bile duct brushings for cholangiocarcinoma in primary sclerosing cholangitis: a systematic review and meta-analysis. Gastrointest Endosc 2014; 79: $783-789$

[96] Navaneethan U, Njei B, Venkatesh PG et al. Fluorescence in situ hybridization for diagnosis of cholangiocarcinoma in primary sclerosing cholangitis: a systematic review and meta-analysis. Gastrointest Endosc 2014; 79: $943-950 \mathrm{e} 3$

[97] Navaneethan U, Njei B, Lourdusamy V et al. Comparative effectiveness of biliary brush cytology and intraductal biopsy for detection of malignant biliary strictures: a systematic review and meta-analysis. Gastrointest Endosc 2015; 81: 168-176

[98] Walker SL, McCormick PA. Diagnosing cholangiocarcinoma in primary sclerosing cholangitis: an "evidence based radiology" review. Abdom Imaging 2008; 33: 14- 17

[99] Karlsen TH, Vesterhus M, Boberg KM. Review article: controversies in the management of primary biliary cirrhosis and primary sclerosing cholangitis. Aliment Pharmacol Ther 2014; 39: 282-301

[100] Nanda A, Brown JM, Berger SH et al. Triple modality testing by endoscopic retrograde cholangiopancreatography for the diagnosis of cholangiocarcinoma. Therap Adv Gastroenterol 2015; 8: 56-65

[101] Fukuda Y, Tsuyuguchi T, Sakai Y et al. Diagnostic utility of peroral cholangioscopy for various bile-duct lesions. Gastrointest Endosc 2005; 62: 374-382

[102] Kawakami H, Kuwatani M, Etoh K et al. Endoscopic retrograde cholangiography versus peroral cholangioscopy to evaluate intraepithelial tumor spread in biliary cancer. Endoscopy 2009; 41: 959-964

[103] Nishikawa T, Tsuyuguchi T, Sakai Y et al. Comparison of the diagnostic accuracy of peroral video-cholangioscopic visual findings and cholangioscopy-guided forceps biopsy findings for indeterminate biliary lesions: a prospective study. Gastrointest Endosc 2013; 77: 219-226

[104] Arnelo U, von Seth E, Bergquist A. Prospective evaluation of the clinical utility of single-operator peroral cholangioscopy in patients with primary sclerosing cholangitis. Endoscopy 2015; 47: 696-702 
[105] Smith MP, Loe RH. Sclerosing cholangitis; review of recent case reports and associated diseases and four new cases. Am J Surg 1965; 110: $239-246$

[106] Broome U, Lindberg G, Lofberg R. Primary sclerosing cholangitis in ulcerative colitis - a risk factor for the development of dysplasia and DNA aneuploidy? Gastroenterology 1992; 102: 1877-1880

[107] Broome U, Lofberg R, Lundqvist $K$ et al. Subclinical time span of inflammatory bowel disease in patients with primary sclerosing cholangitis. Dis Colon Rectum 1995; 38: 1301 - 1305

[108] Broome U, Lofberg R, Veress B et al. Primary sclerosing cholangitis and ulcerative colitis: evidence for increased neoplastic potential. Hepatology 1995; 22: 1404-1408

[109] Soetikno RM, Lin OS, Heidenreich PA et al. Increased risk of colorectal neoplasia in patients with primary sclerosing cholangitis and ulcerative colitis: a meta-analysis. Gastrointest Endosc 2002; 56: 48 54

[110] Broome U, Bergquist A. Primary sclerosing cholangitis, inflammatory bowel disease, and colon cancer. Semin Liver Dis 2006; 26: 31 41

[111] Lindor KD, Kowdley KV, Harrison ME et al. ACG Clinical Guideline: Primary sclerosing cholangitis. Am J Gastroenterol 2015; 110: 646659; quiz 60

[112] Annese V, Daperno M, Rutter MD et al. European evidence based consensus for endoscopy in inflammatory bowel disease. J Crohns Colitis 2013; 7: $982-1018$

[113] Tsaitas C, Semertzidou A, Sinakos E. Update on inflammatory bowel disease in patients with primary sclerosing cholangitis. World J Hepatol 2014; 6: 178-187

[114] Claessen MM, Lutgens MW, van Buuren HR et al. More right-sided IBD-associated colorectal cancer in patients with primary sclerosing cholangitis. Inflamm Bowel Dis 2009; 15: 1331-1336

[115] Vera A, Gunson BK, Ussatoff V et al. Colorectal cancer in patients with inflammatory bowel disease after liver transplantation for primary sclerosing cholangitis. Transplantation 2003; 75: 1983-1988
[116] Jorgensen KK, Grzyb K, Lundin KE et al. Inflammatory bowel disease in patients with primary sclerosing cholangitis: clinical characterization in liver transplanted and nontransplanted patients. Inflamm Bowel Dis 2012; 18: 536- 545

[117] Fausa O, Schrumpf E, Elgjo K. Relationship of inflammatory bowel disease and primary sclerosing cholangitis. Semin Liver Dis 1991; 11: $31-39$

[118] Kaminski MF, Hassan C, Bisschops R et al. Advanced imaging for detection and differentiation of colorectal neoplasia: European Society of Gastrointestinal Endoscopy (ESGE) Guideline. Endoscopy 2014; 46: $435-449$

[119] Subramanian V, Mannath J, Ragunath K et al. Meta-analysis: the diagnostic yield of chromoendoscopy for detecting dysplasia in patients with colonic inflammatory bowel disease. Aliment Pharmacol Ther 2011; 33: $304-312$

[120] Rutter MD, Saunders BP, Wilkinson KH et al. Most dysplasia in ulcerative colitis is visible at colonoscopy. Gastrointest Endosc 2004; 60: $334-339$

[121] Rubin DT, Rothe JA, Hetzel JT et al. Are dysplasia and colorectal cancer endoscopically visible in patients with ulcerative colitis? Gastrointest Endosc 2007; 65: 998 - 1004

[122] Riddell RH, Goldman H, Ransohoff DF et al. Dysplasia in inflammatory bowel disease: standardized classification with provisional clinical applications. Human Pathol 1983; 14: 931 - 968

[123] Connell WR, Lennard-Jones JE, Williams CB et al. Factors affecting the outcome of endoscopic surveillance for cancer in ulcerative colitis. Gastroenterology 1994; 107: 934-944

[124] Ullman TA, Loftus EVJr, Kakar $S$ et al. The fate of low grade dysplasia in ulcerative colitis. Am J Gastroenterol 2002; 97: 922 - 927

[125] Befrits R, Ljung T, Jaramillo E et al. Low-grade dysplasia in extensive, long-standing inflammatory bowel disease: a follow-up study. Dis Colon Rectum 2002; 45: 615-620

[126] Lim CH, Dixon MF, Vail A et al. Ten year follow up of ulcerative colitis patients with and without low grade dysplasia. Gut 2003; 52: 1127 1132 